\title{
The distribution and population dynamics of the honey bee pathogens Crithidia mellificae and Lotmaria passim in New Zealand
}

\section{Tammy Leigh Waters}

\begin{abstract}
A thesis
submitted to the Victoria University of Wellington in fulfilment of the requirements for the degree of Masters' of Science in Cell and Molecular Biology
\end{abstract}

Victoria University of Wellington

Te Whare Wānanga o te Ūpoko o te Ika a Māui 


\section{Abstract}

The honey bee Apis mellifera is experiencing colony losses across the world, this is not the first time in history colony losses have been reported. New molecular detection methods such as real-time PCR allow the detection and analysis of pathogens present in colonies, quickly and reliably.

Of the pathogens that the honey bee is host to, trypanosomes are one of the least understood and trypanosome interactions within the honey bee host remain largely unknown. Using the bumble bee as a model for this host-parasite relationship. The trypanosome $C$. bombi is known to cause a reduced ability to gain nutrients from food and an overall decrease in efficiency of queens in founding colonies in spring. These negative correlations are significant enough in the bumble bee to warrant investigation into trypanosomes in the honey bee.

The trypanosome C. mellificae was first described in the honey bee in 1967. A screening study in 2009 included a test for and detected the trypanosome in modern honey bee samples. In 2013 C. mellificae was identified as a contributory factor to overwintering colony losses when co-infected with $N$. ceranae. Following studies detected trypanosomes and led to the characterisation of a new species, L. passim in 2013. Lotmaria passim was first detected in New Zealand in 2014 however no subsequent studies had been undertaken to identify the distribution and dynamics of trypanosomes in New Zealand honey bee colonies.

My goal in this study was to identify the presence of trypanosomes in New Zealand. In an overview study of 47 honey bee colonies from across New Zealand, 46 were positive for the L. passim species. Identified by sequencing of the GAPDH gene. A yearlong study of 15 colonies revealed that the infection rate of L. passim was consistent throughout the year and very low genetic variation was detected. Lotmaria passim was detected in all parts of New Zealand sampled in this study and often in high levels. A positive correlation was 
detected when L. passim was present in addition to N. apis. There was no detection of C. mellificae in my study. The lack of detection of $C$. mellificae may suggest that the species is not present, or that it is in such low levels it cannot yet be detected.

In parallel to this trypanosome study two Nosema spp. and DWV were also examined. Nosema apis was found to be more prevalent than N. ceranae, which was not present in any South Island samples. A strong positive correlation was detected between the two Nosema spp. DWV showed a high level of variation likely a reflection of differing Varroa management practices in apiaries in this study.

This study of trypanosomes is the first of its kind in New Zealand identifying the presence and population dynamics of L. passim. This in conjunction with data on Nosema spp. and DWV will be of value to the New Zealand apiculture industry and contribute to global honey bee health studies. 


\section{Acknowledgements}

Thank you to Professor Phil Lester for taking me on as a student and for giving me the encouragement to choose a project that I would enjoy. I appreciate the time you have spent assisting me with my studies. Many thanks to Dr James Baty who assisted with data and statistical analyses.

I could not have completed this study without the support of John and Belinda Mackay of dnature diagnostics \& research Ltd. Thanks John for answering my constant questions about real-time PCR, how to design primers, and how to figure out what all those sequences meant. Your patience and understanding has kept me focused and helped me succeed in this study, I am grateful to you and Belinda for having the confidence in me that at times I could not find in myself.

Thanks Jess Russell for being a positive and happy influence. I could not have put together a phylogenetic tree without you Evan Breton-Rule thanks for sharing your knowledge. Also, thanks to John McLean for the honey bee anatomy lesson and to Barry Foster for providing field experience.

A special thank you goes out to all the beekeepers who contributed to this study. I appreciate you taking the time to collect samples, especially for those of you who were in it for the year study - the long haul is over, and I couldn't have done it without you. I have gained a greater appreciation for what is required of a beekeeper, the knowledge you can pass on will be invaluable to researchers now and in the future.

Thanks to Apiculture New Zealand for allowing me to share my study at the beekeeping conference in 2017. And thank you to the Todd Foundation for the generous scholarship which enable me to complete my research. 
Thank you, Jo, Steve and Scott at Far East Coffee, for keeping me caffeinated and in high spirits. And to the lovely Catherine Breeze for sharing and enabling the coffee addiction, your always welcome in the lab and I feel blessed to count you as a friend and colleague. 


\section{Table of Contents}

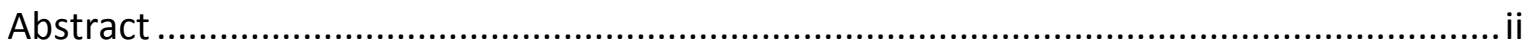

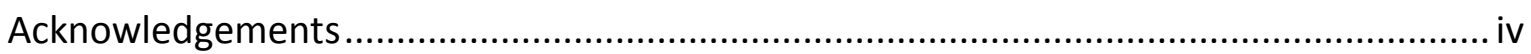

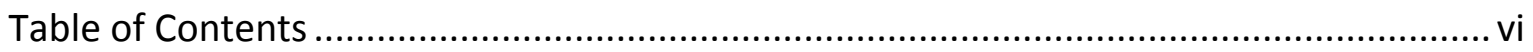

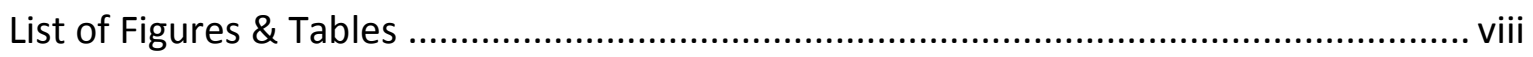

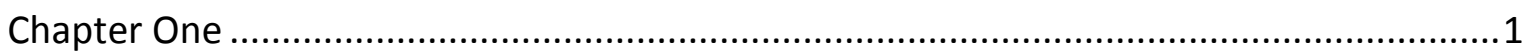

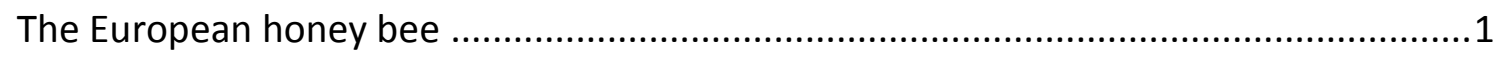

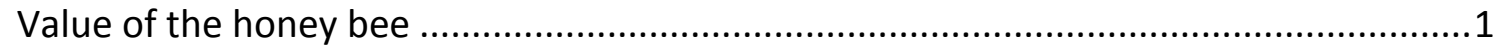

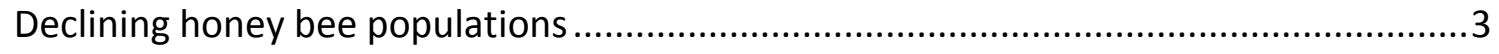

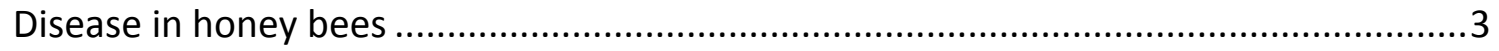

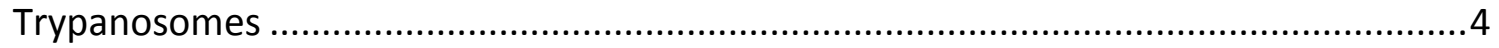

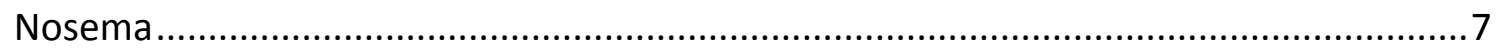

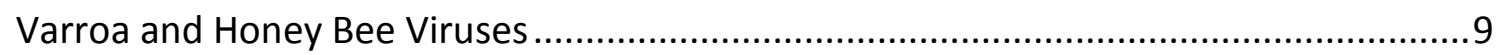

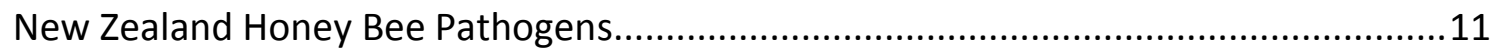

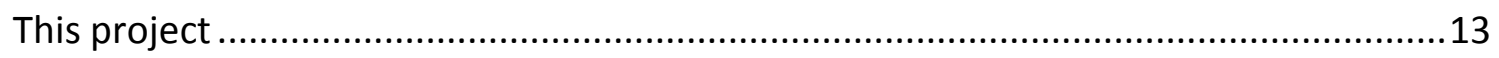

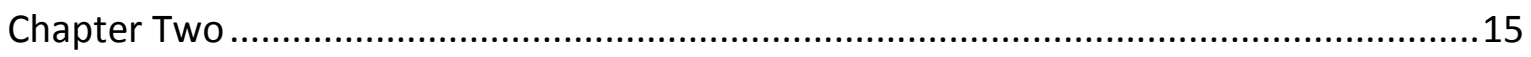

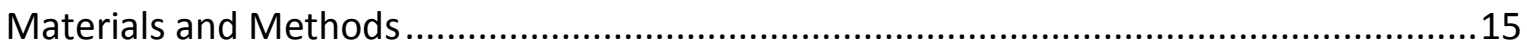

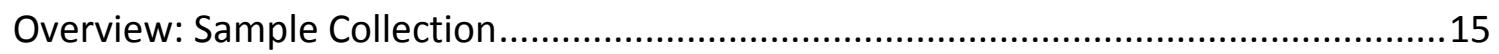

Evaluation of number of honey bees required for extraction ....................................15

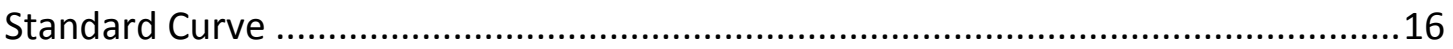

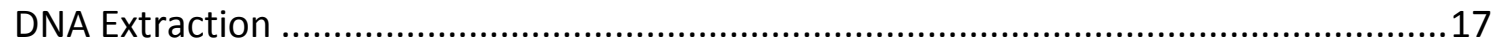

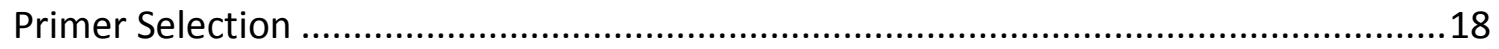

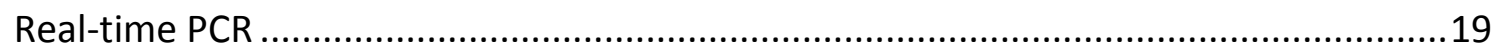




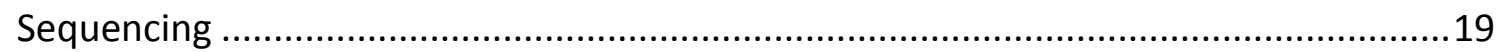

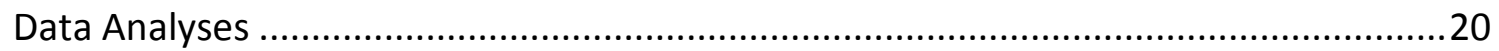

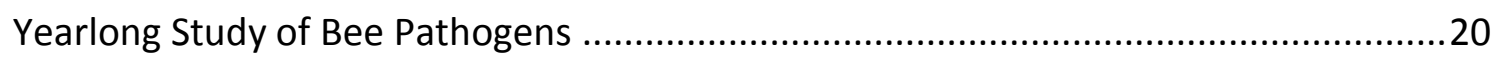

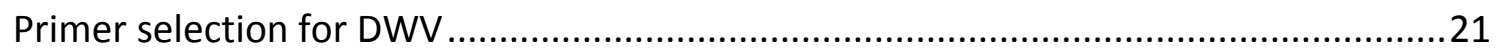

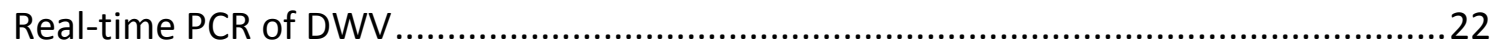

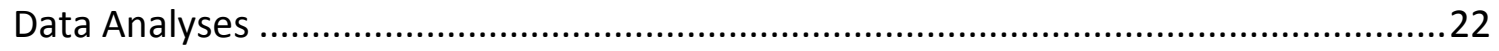

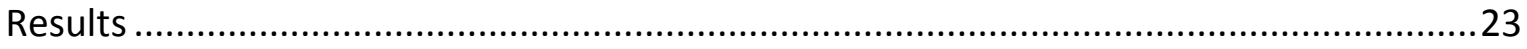

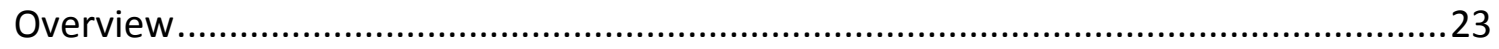

Identification and Distribution of Trypanosomes in New Zealand............................23

Identification of the Trypanosomes C. mellificae and L. passim ..............................23

Distribution of pathogens N. apis, N. ceranae and DWV .........................................26

Population dynamics of L. passim, two Nosema spp. and DWV ..................................27

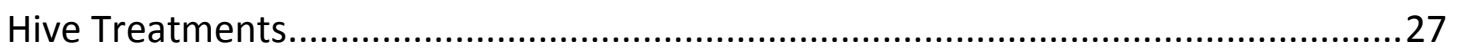

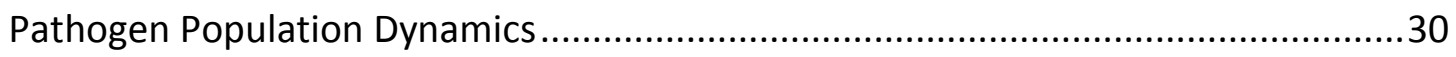

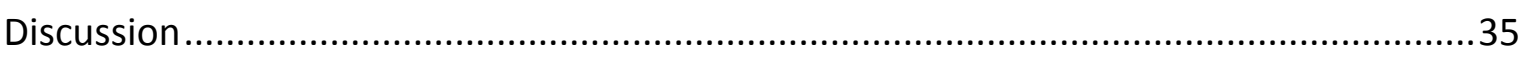

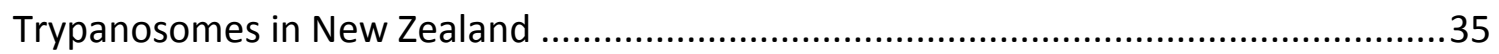

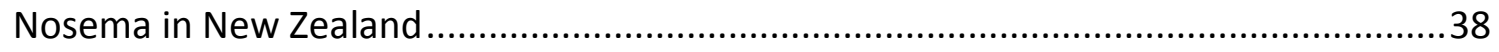

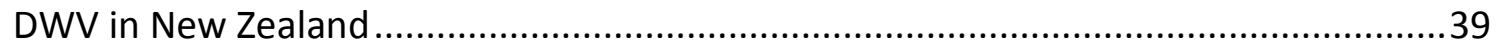

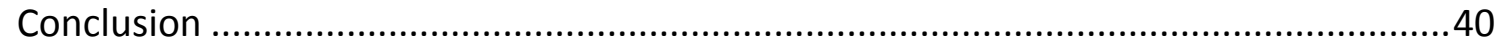

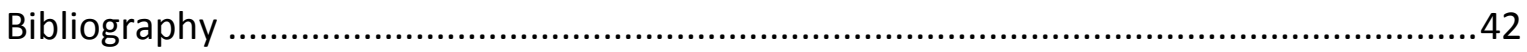

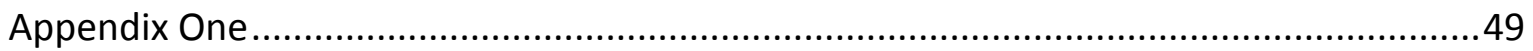

Evaluation of number of honey bees required for extraction................................49

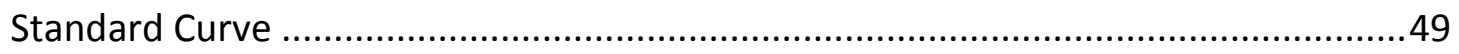

Real-time PCR efficiency by standard curve ....................................................50

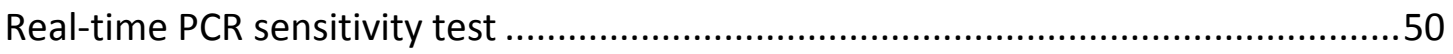




\section{List of Figures \& Tables}

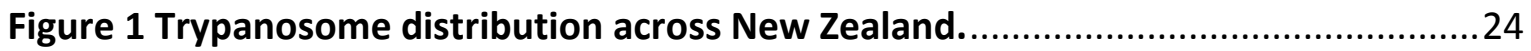

Figure 2 Molecular Phylogenetic analysis by Maximum Likelihood method ...................25

Figure 3 Distribution of other pathogens in New Zealand ...........................................26

Figure 4 Prevalence of $L$. passim and other pathogens over times...............................28

Figure 5 Relative abundance of four pathogens in three New Zealand regions..............31

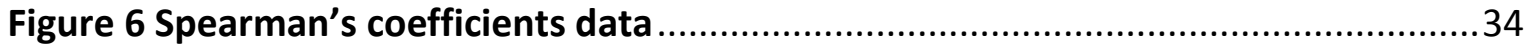

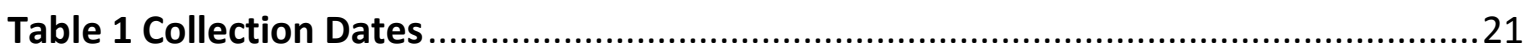

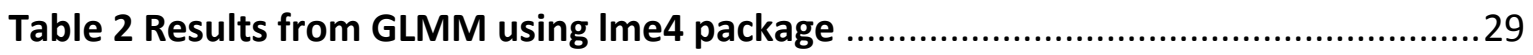

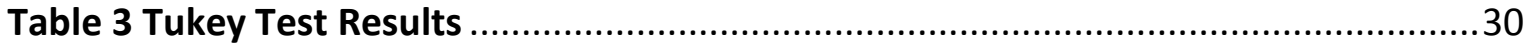

Table 4 Results from repeated measures ANOVA on log-transformed pathogen abundances over time. 


\section{Chapter One}

\section{The European honey bee}

The European honey bee Apis mellifera is the most well-known species of bee in the world (Meixner, 2010). The popularity stems primarily from the domestication of the bee to produce honey. Archaeological evidence suggests that beekeeping for honey production dates back to at least as early as the Ancient Egyptians circa 2500BC (Meixner, 2010). The continued demand for honey has led to modern beekeeping and the distribution of honey bees across the world, entering every continent except Antarctica (Moritz et al., 2005).

The honey bee hive is developed by the queen bee which gives rise to all of the bees in the hive (Higes et al., 2008; Winston, 1991). Newly emerged bees remain in the hive to tend the developing larvae. Newly emerged bees consume pollen, leading to development of hypopharyngeal glands which produce jelly, a food source for larvae (Loidl and Crailsheim, 2001). When the honey bee is around 7 days old they move on to other duties within the hive. These duties include storing pollen, nectar and water, and protecting the hive as guard bees. Collecting food and water to support the colony as foragers is the last duty of a honey bee and occurs at approximately 21 days (Page et al., 2006).

\section{Value of the honey bee}

Honey production is now a valuable industry, honey is produced by bees through the collection of nectar from plants and flowers (Matheson and Reid, 2011). The nectar by forager bees is transferred to storer bees in the hive by trophallaxis and then regurgitated into honey comb cells (Wright et al., 2017). The nectar is dried by bees fanning their wings, once enough moisture is reduced the honey is capped with wax for storage (Matheson and Reid, 2011). A honey bee colony can produce tens of kilograms of honey, depending on the success of the season (Wright et al., 2017). 
In addition to honey production bees are highly valued as pollinators (Calderone, 2012). Pollination is critically important to the agricultural industry providing essential pollination services for many crops (Klein et al., 2007). Bee pollination is necessary in $75 \%$ of food crops (Bommarco et al., 2013; Potts et al., 2010). Whilst foraging for nectar and pollen, powdery pollen clings to the hairy body of the bee and is transferred to other flowers leading to pollination (Grissell, 2010).

Human population growth has driven the need for an increase in food crops. This demand has led to the development and expansion of large single yield crops and orchards called monocultures (Bommarco et al., 2013). This agricultural growth has in some cases exceeded the pollination ability of local honey bee populations (Aizen and Harder, 2009; Bommarco et al., 2013). In response to increasing demand for pollination services, managed honey bee services have been established across the world (Gallai et al., 2009).

One of the largest pollination events occurs in California USA, where $80 \%$ of the worlds almonds are produced (Klein et al., 2012). One million acres of almonds require pollination by 2 million honey bee colonies (Traynor, 2017). With only 500,000 colonies in California, managed honey bee colonies are migrated into California for the February pollination event (Traynor, 2017). The almond crops of 2014 were worth $\$ 7.6$ billion USD (Sumner et al., 2014). The economic value of honey bee pollination in the United States in 2009 was \$11 billion an increase of approximately 40\% since 2001 (Calderone, 2012).

The United Nations recorded an increase in domestic honey bee colonies of approximately $45 \%$ since 1961 , despite the global increase in honey bees, regional declines of $59 \%$ in the USA and 25\% in Europe have been recorded as of 2015 (Aizen and Harder, 2009; Potts et al., 2010). Drivers for these losses were previously identified by Potts et al. (2010) as loss of habitat due to increased agriculture and the use of agrochemicals, the impact of pathogens, climate change, and alien species impact on honey bee health, especially the Varroa destructor mite. 


\section{Declining honey bee populations}

Declining honey bee populations have been reported across the world, with losses attributed in part to honey bee pathogens (Cox-Foster et al., 2007; Meixner, 2010; Potts et al., 2010; vanEngelsdorp et al., 2009b). This is not the first-time populations have been affected, as described by Oldroyd (2007), the Isle of Wight lost $100 \%$ of their colonies in 1906. Similarly, the United States in 1903 lost 2,000 colonies due to a hard winter in Utah, and in 1995 over 50\% of colonies in Pennsylvania were lost. In October of 2006 a beekeeper in Florida found 368 out of the 400 colonies in his apiary almost empty. In the hives only the queen, a few young bees and brood remained. There were adequate stores of food and no dead bees found around the hives. This incident was the first on record of what is now known as Colony Collapse Disorder (CCD) (Stokstad, 2007).

This first report in 2006 of CCD has been described by Cox-Foster et al. (2007) as colonies exhibiting fast loss of adult honey bees with only a few remaining bees attending the queen and brood. Food stores could be present, and no dead bees found in and around the hive (vanEngelsdorp et al., 2009b). To better understand CCD vanEngelsdorp et al. (2009a) compared bee physiology, pathogens and pesticide loads between affected and unaffected colonies. Colonies affected by CCD had higher pathogen loads exhibiting higher co-infection with neighbouring colonies being less strong than expected, potential evidence of CCD being contagious or arising from a common risk factor. Despite these observations no single attribute was found to be responsible for CCD (vanEngelsdorp et al., 2009a).

\section{Disease in honey bees}

Honey bees are susceptible to a variety of pathogens. The first published case of CCD in 2006 and the losses during the winter of 2007-2008 in the United States led to a plethora of sampling and testing of possible factors contributing to the losses (Stokstad, 2007). More recent work on CCD by Cepero et al. (2015) investigated pathogens affecting colonies in Spain in 2013. They found CCD colonies showed a significantly higher infection by the pathogen Nosema ceranae than control colonies. Evidence indicates that high pathogen load and co-infection are more common in CCD apiaries. This study was one of the first to 
identify the trypanosome Crithidia mellificae as a pathogen related to CCD and honey bee health. Trypanosomes have been described in these studies as pathogens and for this study will be referred to as pathogens.

In addition to trypanosomes, the fungal parasites Nosema apis and $N$. ceranae are included in many studies of colony loss, with the potential for these pathogens to work in synergy to lessen the honey bees life span (Evans and Schwarz, 2011). Several viruses are associated with colony losses, the most common being Deformed Wing Virus (DWV) first identified in Japan and is now distributed across the world. DWV is often found in association with the Varroa mite, both being linked to colony loss (Lanzi et al., 2006).

\section{Trypanosomes}

Trypanosomes have been well described by Agnew et al. (2003) as microsporidians which grow and reproduce only within the host cells. As obligate parasites they require the host environment for energy and nutrients to reproduce. Trypanosomes reproduce by creating spores which germinate in the appropriate environment. Germination triggers the extension of a polar filament capable of piercing nearby host cells. Once a host cell is pierced pressure develops within the germinating spore, resulting in the spore cell contents being forced down the polar filament and into the host cells cytoplasm. Once inside the host cell the spore will reproduce until the host cell ruptures. Trypanosomes are able to migrate into other host tissues through blood and haemolymph and are passed into the environment through defecation (Agnew et al., 2003).

Trypanosomes have been well studied in bumble bees. Crithidia bombi a trypanosome infecting bumble bees is often referred to as a model for host-parasite interactions (Koch and Schmid-Hempel, 2011). The effects of $C$. bombi on the bumble bee in Switzerland were at first thought to be negligible, however, once a bumble bee queen becomes stressed they begin to show adverse effects of the parasitism (Brown et al., 2003; Yourth et al., 2008). These effects are a reduced ability to carry pollen, reduced growth and higher mortality (Koch and Schmid-Hempel, 2011). Further studies revealed that infected bumble bees take longer to access nectar from flowers and can affect a queen bees ability to found a new 
colony in spring (Brown et al., 2003; Gomez-Moracho et al., 2017; Yourth and SchmidHempel, 2006). The honey bee is a known vector for the transmission of C. bombi (Graystock et al., 2015).

In comparison, honey bee colonies, which do not die off over winter, can build-up infection in the hive over winter and spring. A majority of colony loss occurs over winter (Yourth and Schmid-Hempel, 2006). The European honey bee A. mellifera is host to the trypanosome C. mellificae. The species was first described in Australia in 1967 as part of a diagnostic project. The motile organism was found in the hind gut and identified using morphology by light microscopy (Langridge and McGhee, 1967).

Trypanosomes have known negative effects on bumble bees, and with concerning honey bee colony losses investigations into trypanosomes in honey bees became of interest. A screening study into CCD by Cox-Foster et al. (2007) identified the presence of several pathogens including a trypanosome in honey bees in the United States of America. The species could not be determined, therefore it was attributed to the Leptomonas-Crithidia lineage (Cox-Foster et al., 2007). Subsequent studies by Evans et al. (2009) into CCD affected colonies from the 2007-2008 winter colony losses in the USA detected trypanosomes in all samples, both control and CCD affected colonies.

A study by Runckel et al. (2011) focused on identifying the "normal" pathogen loads of honey bee colonies. Honey bees were sampled from 20 migratory colonies from April 2009 to January 2010. The trypanosome C. mellificae was detected and identified for the first time since 1967. Analyses identified C. mellificae in every sample with peak infection occurring in January 2010. There was no correlation detected between the presence of C. mellificae and colony losses. There was however a positive correlation found between N. ceranae and C. mellificae infection. This correlation and the known detrimental effects of $C$. bombi on bumble bee colonies emphasised the importance of further investigations into trypanosomes effects on honey bee health (Runckel et al., 2011). A review by Evans and Schwarz (2011) reinforced the need to investigate the population dynamics, prevalence and effect of trypanosomes and especially C. mellificae on bees. 
Soon after $C$. mellificae was identified in honey bee samples and as a potential factor in honey bee health, a screening study of pathogen webs in honey bees by Cornman et al. (2012) identified trypanosomes in CCD affected and unaffected colonies. Unfortunately, many trypanosome and other species were detected and incorrectly attributed as being C. mellificae. They were more likely from the closely related Leishmania and Leptomonas clades, indicating a more stringent test for trypanosome detection was needed (Cornman et al., 2012).

Large colony losses also occurred in Belgium, with almost $50 \%$ of colonies lost during the 2011-2012 season. A study by Ravoet et al. (2013) was the first to re-examine historic honey bee samples to detect a possible predictor for CCD. Results identified the Varroa mite as the largest contributor to $\mathrm{CCD}$ and a negative synergistic effect between Varroa, $N$. ceranae and C. mellificae. The study concluded C. mellificae as a contributing factor to over wintering colony losses in Belgium (Ravoet et al., 2013).

Re-examination of historic bee samples from Japan taken April 2007 - February 2012 detected $C$. mellificae in the European honey bee A. mellifera but not in the Asian honey bee Apis ceranae (Morimoto et al., 2012). Chinese studies surveyed colonies from November 2011 - September 2012 where C. mellificae was detected in A. ceranae for the first time, indicating that $C$. mellificae is either carried by or infects more than one bee species (Yang et al., 2013). Samples analysed from Italy and Spain also identified C. mellificae (Cepero et al., 2014; Cersini et al., 2015). Further analysis of the GAPDH gene in bees from Spain showed a large genetic distance between it and the original culture strain ATCC30254 from Australia (Langridge and McGhee, 1967). This indicates study samples may be from a completely difference taxon and could require reclassification (Cepero et al., 2014).

The indication of reclassification from Spanish samples led to two trypanosome cultures being characterised by Schwarz et al. (2015) in the Bee Research Laboratory (BRL) in Maryland. The study compared the original 1967 culture ATCC30254 to the BRL and San Francisco (SF) strains. From this comparison the novel species Lotmaria passim was 
characterised as distinct from C. mellificae. The newly identified L. passim was named in honour of the entomologist Dr. Ruth Lotmar with the addition of the suffix 'ia' to show the organisms close relationship to Crithidia and Leishmania clades (Schwarz et al., 2015).

Since the characterisation of L. passim as a novel species Ravoet et al. (2015) re-examined samples from Belgium, Japan, Spain, Switzerland and Turkey and found L. passim present in each sample. Most samples showed a mix of $C$. mellificae and L. passim with the latter being predominant. The only country known to have honey bees that are only infected with C. mellificae to date is Belgium (Ravoet et al., 2015). Several countries have re-examined historic samples and identified a majority of the species attributed as $C$. mellificae should be reclassified as L. passim (Cavigli et al., 2016). Studies from Chile and Serbia have detected L. passim as far back as 2007 demonstrating L. passim is the predominant trypanosome in A. mellifera in these regions (Arismendi et al., 2016; Stevanovic et al., 2016).

Data from Switzerland by Tritschler et al. (2017) on pathogen interactions showed no correlation between L. passim and the two Nosema spp. which had been previously described in studies of C. mellificae in the United States (Evans and Schwarz, 2011; Tritschler et al., 2017). However, new data from Vejnovic et al. (2017) indicates that L. passim and $N$. ceranae exhibit similar trends over-time demonstrating infection level peaked in winter with drops in summer.

\section{Nosema}

Nosema spp. are microsporidians that parasitise insects and other invertebrates (Agnew et al., 2003; Li et al., 2016). These microsporidians require the environment of the host cell for energy and nutrients, sourced from host mitochondrial cells (Li et al., 2016). The microsporidian lifecycle described by Agnew et al. (2003) begins as a spore with germination initiating the reproduction cycle similar to trypanosomes. The spores produced may germinate and reinfect the host or be passed in the host faeces. In some cases spores can migrate to other parts of the host, still it has not been shown that spores in these locations are able to reproduce (Copley and Jabaji, 2012). Microsporidians are 
known to adapt to ensure success within the host, the parasite-host relationship co-evolves overtime to ensure survival of both organisms (Agnew et al., 2003). When a parasite infects a new species there is no co-evolutionary relationship and the parasite may kill a species that has not previously hosted it, or a similar, parasite (Le Conte et al., 2010).

Whilst foraging a bee may collect Nosema spores on their hairy bodies and carry them back into the hive (Paxton et al., 2007). Spores enter the digestive tract of the honey bee during grooming then germinate in the mid gut producing a parasite with a flagellum. The flagellum provides motility and is used to infect epithelial cells of the host (Higes et al., 2007b; Holt and Grozinger, 2016). Nosema spp. spores and parasites may remain in the honey bee mid gut to gain nutrition from the host for reproduction and are then passed in faeces (Chen et al., 2009). As the parasite continues to reproduce the host exhibits negative effects. The Nosema spp. effects on the honey bee reduces its life span through energetic deprivation reducing ability to forage and return to the hive (Holt and Grozinger, 2016).

Nosema apis has been associated with A. mellifera in Europe since 1909 and is now detected worldwide (Fries et al., 2006). While typically not considered highly virulent it can shorten the honey bee lifespan, weakening heavily infected colonies (Klee et al., 2007). The microsporidian N. ceranae was first described in the Asian honey bee A. ceranae in 1994 (Chen et al., 2009; Fries et al., 1996). A study from Europe determined N. ceranae has been infecting A. mellifera since 1998 (Paxton et al., 2007). Identification of $N$. ceranae in the European honey bee indicates that co-infection by both Nosema microsporidians can occur in A. mellifera (Klee et al., 2007).

Due to the recent crossover from Asian to European honey bee $N$. ceranae is known as an emergent pathogen of $A$. mellifera (Paxton et al., 2007). As explained in a study by MartínHernández et al. (2011), N. ceranae has not co-evolved with A. mellifera and the metabolic needs of N. apis which has infected bees since the 1900's are not the same. Increased feeding by infected bees shows the pathogen $N$. ceranae requires more energy to reproduce. The energetic stress can reduce the bees' lifespan and degrade health of the gut tissues in the host (Martín-Hernández et al., 2011). 
Due to the two Nosema spp. infecting the mid gut of honey bees it is likely that they will compete for resources (Cornman et al., 2012). A cage study by Forsgren and Fries (2010) where honey bees were co-infected with the two Nosema spp. demonstrated no clear advantage for either. A study in which newly hatched honey bees are infected with the two Nosema spp. by Natsopoulou et al. (2015) demonstrated interspecific competition when species are introduced at different times. The first introduced species inhibiting the growth of the next, however $N$. ceranae infection more strongly inhibited that of $N$. apis.

Several studies have identified co-infection of some or all the honey bees tested with the two Nosema spp. As $N$. ceranae can infect tissues outside of the gut such as the brain and hypopharyngeal glands, this may yield a higher overall infection level as there are more tissues for this species to invade in comparison to N. apis (Gisder et al., 2010). Infection by the two Nosema spp. have shown a predominance of, or suspected replacement of, $N$. apis by N. ceranae (Gisder et al., 2010). There has not been any additional correlation to support this theory and further research into Nosema spp. dynamics in honey bees and with other pathogens is needed (Dainat et al., 2012; Gisder et al., 2017; Vejnovic et al., 2017).

\section{Varroa and Honey Bee Viruses}

Of the threats to honey bee health the mite Varroa is well-known. The mite originated in Asia where it co-evolved with the Asian honey bee A. ceranae (Rosenkranz et al., 2010). Since its introduction to A. mellifera the Varroa mite has spread rapidly across the globe. Infection has been attributed to colony losses in Europe the UK, USA and New Zealand. Australia as yet remains uninfected (Mondet et al., 2014). The parasitism of Varroa described by Rosenkranz et al. (2010) shows it occurs in brood comb cells, mites feed on larvae then hatch along with the damaged honey bee. Once free in the hive Varroa repeatedly inject adult honey bees to enable feeding on bee haemolymph, causing physical injures and leaving open wounds. Mite feeding on bee haemolymph reduces bee protein stores and negatively affects organ development, resulting in honey bees with reduced energy and life span. The mite also acts as a vector transmitting viruses between honey bees (Le Conte et al., 2010). 
Studies from the United States by Martin et al. (2012) found that after infection by Varroa the incidence of DWV in honey bee colonies increased from 6-13\% to $75-100 \%$ in Hawaii. The genetic diversity of DWV was over time reduced to a strain which is highly infectious. The evolution of this highly virulent DWV strain was selected for through the actions of the Varroa mite infection in Hawaii (Martin et al., 2012). DWV is an important virus in honey bee colony health, as it has been known to shorten the life span since the early 1980's (Lanzi et al., 2006). If there is an absence of Varroa a lower accumulation of DWV will typically occur via horizontal transmission through bees in the colony (Ryabov et al., 2014). The Varroa mite is responsible for not only the rapid global distribution of DWV but also of other viruses related to colony losses (De Miranda and Genersch, 2010).

Black Queen Cell Virus (BQCV) is known to be the most common cause of death in queens in Australia, named such because infected cells show darkened areas (Benjeddou et al., 2002). The infection of BQCV can cause an enlarged abdomen along with jerky movements. When associated with $N$. apis there is evidence this virus can increase bee mortality rates (Benjeddou et al., 2002; Higes et al., 2007a). Chronic Bee Paralysis Virus (CBPV) symptoms are, trembling bees which may also become dark and hairless (Ribière et al., 2002). The virus can cause flightlessness which will lead to dead bees outside of the hive, CBPV is known to cause significant honey bee losses (Olivier et al., 2008; Ribiere et al., 2007). The most virulent virus in the laboratory, Kashmir Bee Virus (KBV), has been associated with colony collapse and can exhibit no symptoms in infected bees (De Miranda et al., 2004). Detected in 1974 the virus is known to persist in honey bee populations at non-lethal levels although the effects on honey bees in the field remain unknown (Evans, 2001).

Honey bees harbour many pathogens. As colony losses continue to occur further research into pathogen interactions in the honey bee will elucidate the causes of losses, which will be of great importance to honey bee health (Higes et al., 2007b). With new tools for molecular detection detailed studies on pathogens will enable greater understanding of honey bee health and what can be done to ensure the health of honey bees now and in the future (Evans and Schwarz, 2011). 


\section{New Zealand Honey Bee Pathogens}

In New Zealand there is a strong beekeeping industry with the first domesticated bees arriving with English colonists 1839 for honey production. There are approximately 41 species of native bees in New Zealand, none of which have been commercialised. Apis mellifera is the dominant managed bee in New Zealand (Donovan, 2007). According to the New Zealand Colony Loss Survey 2016, $80 \%$ of New Zealand hives are primarily for honey production with $20 \%$ also being used to provide pollination services (Brown, 2016). Pollination services are provided for crops which are vital to the agricultural industry, and to the dairy industry through the pollination of pastures of white clover. The yearly value of which is estimated at $\$ 3,000$ million (Donovan, 2007). Honey production for export is lucrative as reported by the Primary Production Committee (2014) honey exports were worth $\$ 145$ million in 2013 , an increase of approximately $20 \%$ on the previous year. The increase mainly due to demand for Mānuka honey which has medical benefits sought after worldwide (Chan et al., 2013).

The introduction of honey bees also brought honey bee pathogens to New Zealand (Mondet et al., 2014). To date the most monitored pathogen invasion has been that of N. ceranae, and the incursion of the Varroa mite which acts as a vector for honey bee pathogens (Mondet et al., 2014). The largest colony losses in New Zealand occurred in the Coromandel region during 2014-2015 a beekeeper reported significant reduction in honey bee numbers over a month with an estimated reduction in honey bees numbers of 10,000 down to 1,000 (McFadden A, 2016). Testing was conducted by the Ministry for Primary Industries (MPI) on the remaining live bees which identified the presence of the two Nosema spp. and L. passim, the first detection in New Zealand. Further losses were reported that year and testing showed many were positive for the two Nosema spp. with 75\% also testing positive for L. passim (McFadden A, 2016).

In contrast to N. apis, N. ceranae was only detected in New Zealand in 2010, however details of its introduction into New Zealand remain unknown (Murray and Lester, 2015). The two Nosema spp. have been implicated in global colony loss overseas, however no evidence to date has been found to suggest this in New Zealand. The investigation by MPI 
into colony losses in the Coromandel showed that both healthy and declining colonies are infected with the two Nosema spp. (McFadden A, 2016; Murray and Lester, 2015). More research is required as global trends indicate the two Nosema spp. are linked to colony loss (Cepero et al., 2015).

The recent arrival of Varroa in New Zealand has prompted study into the effects of this incursion and the overall health of New Zealand honey bees. The arrival of Varroa in New Zealand began in the upper North Island in the year 2000. The government attempted to reduce the spread of the mite by imposing movement controls. This did not stop the spread of Varroa and as of 2013 most areas of New Zealand are now infected with the mite (Mondet et al., 2014). The arrival of the mite is estimated to impact New Zealand's agricultural production in the order of $\$ 400-900$ million over the next 35 years (Goodwin, 2004).

Research by Mondet et al. (2014) examined the spread of the mite and its effect on viruses of honey bees since its detection ten years prior. The mite carried with it DWV, BQCV, and KBV which may co-infect honey bees. These viruses have been implicated in colony losses. Higher mortality rates are often described when bee colonies are co-infected with mites in addition to other pathogens (Todd et al., 2007) Of these viruses DWV is now the most predominant in New Zealand found in $85 \%$ of colonies indicating that viral succession may have left a predominant DWV in New Zealand honey bees (Mondet et al., 2014).

Since this first detection of L. passim in New Zealand (McFadden A, 2016) no research has been undertaken to identify the distribution or genetic diversity of the trypanosome. Due to New Zealand's geographic isolation there may be a single or several strains of trypanosomes which remain undetected. As trypanosomes have been linked to overwinter colony loss (Ravoet et al., 2015) and found in association with N. ceranae, identification of the infection in New Zealand and interactions with these other pathogens will be of great value to apiculture industry of New Zealand. 


\section{This project}

This project will identify trypanosome species and their distribution and prevalence in New Zealand. I will also analyse samples for two Nosema spp. and DWV which will provide information on pathogen interaction and dynamics in New Zealand. The two Nosema spp. are globally well studied honey bee pathogens identified as factors in colony loss (Cavigli et al., 2016; Evans and Schwarz, 2011). DWV is strongly associated with colony loss more so when found in the presence of the Varroa mite. DWV has recently been identified in mixed infections of honey bees with L. passim, both showing a preference for cooler climates (Vargas et al., 2017). None of these pathogens have been well studied in New Zealand.

Aim One: $\quad$ Determine if the trypanosomes L. passim and C. mellificae are present in New Zealand honey bees and examine their genetic diversity.

Determine if sites are co-infected with the two Nosema spp. and DWV.

Aim Two: Determine if the infection level and/or species diversity of the trypanosomes present changes over the course of a year within colonies in New Zealand.

Determine if the two Nosema spp. and DWV vary in relation to trypanosome infection in honey bees.

This is the first project of this kind in New Zealand detecting trypanosomes and their population dynamics over a year. Detection of the two Nosema spp. will run in parallel with the trypanosome study to determine if there is any co-variance of significance. Expected results may be similar to those seen in other countries, with L. passim being predominant over C. mellificae (Tritschler et al., 2017; Vejnovic et al., 2017). However, with New Zealand being geographically close to Australia where $C$. mellificae was first described (Langridge and McGhee, 1967), the species may be present and unchanged. The genetic diversity of trypanosomes will be of interest and could elucidate where the infection in New Zealand originated. Any diversity could also lead to identification of new clades of trypanosomes and identify any virulence between species. 
As trypanosomes have been identified as factors in colony loss it is important to determine the levels of infection in New Zealand to protect our honey bee health. Research into the distribution and prevalence of trypanosomes and its interactions with other pathogens will produce valuable information for the apiculture industry. 


\section{Chapter Two}

\section{Materials and Methods}

This project aimed to identify if the trypanosomes, $C$. mellificae and L. passim were present in New Zealand and their genetic diversity. This goal was achieved by taking an overview of samples from across New Zealand.

The methods for this project contain some results which were used to optimise the study sampling process and are included here.

\section{Overview: Sample Collection}

To obtain samples from across New Zealand at the same time, beekeepers were recruited through an online request on the New Zealand Beekeepers forum (www.nzbees.net). Beekeepers were asked to collect a sample of 100 honey bees from a single hive on 11 November 2016. Worker honey bees were to be brushed off the comb and collected into a container or zip-lock bag before being frozen at $-20^{\circ} \mathrm{C}$. Samples were kept frozen and then couriered on ice to the laboratory in Gisborne no longer than 5 days after collection. A total of 47 samples were received and logged, if not tested immediately, samples were stored at $-20^{\circ} \mathrm{C}$ for a period no greater than seven days prior to RNA/DNA extraction.

\section{Evaluation of number of honey bees required for extraction}

The number of honey bees used in DNA extraction and real-time PCR testing varies across studies. A variety of studies have used anywhere from a single bee to 100 bees per sample for analysis (Cepero et al., 2014; Ravoet et al., 2013; Tritschler et al., 2017). An evaluation of the number of honey bees required for a representative subset of the 100 bee samples was undertaken to enable a percentage of the sample remained for additional testing, if required. In addition, PCR standard curves were generated for each pathogen tested and 
the respective reference genes to enable the normalisation of quantification cycle $(\mathrm{Cq})$ data and optimisation of real time PCR testing (Appendix One).

To determine the number of bees that gave the best representative subset, a comparison between 10, 40 and 80 honey bees was completed, see Appendix One for these data, which indicated that 40 bees would be the most appropriate representative subsample for this study.

\section{Standard Curve}

Standard curves for each of the pathogens and the reference genes were generated using a standard ten-fold dilution of a combined positive sample (Evans et al., 2013). Each cycle of real-time PCR if performing at $100 \%$ efficiency should produce two amplicons from one, this would demonstrate the real-time PCR test it its optimal level. In this study, by using ten-fold dilutions a standard curve should give Cq values which differ by $\sim 3.32$ cycles, indicating $100 \%$ efficiency, for each sample in the dilution series. However there is an acceptable limit that standard curves should fall within which are between $90-110 \%$ this will ensure a robust and precise real-time PCR reaction (Taylor et al., 2010).

In addition to efficiency values, the $\mathrm{R}^{2}$ and $\mathrm{y}$-intercept values provide support to robust real-time PCR efficiencies. The $\mathrm{R}^{2}$, a coefficient of determination, shows how well the data fit the linear regression line. Any significant differences in Cq value lowers the $R^{2}$ value, which should be $>0.980$ to represent an acceptable real-time PCR reaction (Taylor et al., 2010). Finally, a y-intercept value of between -3.50 and -3.10 provides robust support to an efficient real-time PCR (Bustin et al., 2009; Taylor et al., 2010). An example of a standard curve generated and the associated data in this study is shown in Appendix One.

Real-time PCR Cq data were compiled and the reference genes $\beta$-actin and RPS5 were used to normalise variations between DNA \& RNA in samples as described by Pfaffl (2001). 
The Minimum Information for Publication of Quantitative (MIQE) real-time PCR standards by (Bustin et al., 2009) were used to identify which real-time PCR primer sets would gave the most sensitive results. To achieve this goal, the first eight samples collected were compared using qCrFwd1/Rev1 primers and a commercial Trypanosome Kit by dnature diagnostics \& research Ltd (dnature). Determining factors were real-time PCR identification of trypanosome at $\mathrm{Cq}>30$ which indicate greater sensitivity of the real-time PCR at low copy numbers. Also taken into account was DNA purity by spectrophotometry which indicates purity of DNA and lack of contamination from the extraction process available in Appendix One (Bustin et al., 2009).

Results for the first eight samples tested are shown in Appendix One, samples with Cq of > 38 are considered not detected (ND) due to the potential for these to be amplifications of low level non-target genes. These data show that the Trypanosome Kit (dnature) was more sensitive at detecting lower copy numbers as highlighted in samples 6 and 8 which gave not detected results using the qCrFwd1/Rev1 primer set (Appendix One). The first eight samples were tested using the DS-11 Spectrophotometer (DeNovix, Delaware USA) and were shown to contain uncontaminated, pure DNA. Sample three was sequenced and identified as the trypanosome L. passim. All these tests indicate that the Trypanosome Kit (dnature) likely provided the greatest sensitivity after which testing continued using only the Trypanosome Kit (dnature)

\section{DNA Extraction}

Forty bees in total were homogenised from each sample. To achieve this sample, ten bees were added to four $7 \mathrm{ml}$ bead beating tubes. Each $7 \mathrm{ml}$ tube contained $2 \times 6 \mathrm{~mm}$ stainless steel ball bearings, $3 \mathrm{ml}$ of CTAB (1M Tris, pH8.0; 0.5M EDTA, pH8.0; CTAB powder, $\mathrm{NaCl}$, PVP-40), and $30 \mu \mathrm{l}$ of $1 \mathrm{M}$ Sodium Meta Bisulphate (SMB). Tubes were homogenised for 1 minute using the MiniBeadBeater16 (BioSpec, Oklahoma, USA) and then incubated at $65^{\circ} \mathrm{C}$ for 10 minutes, with mixing every two minutes. From each of the four tubes, $250 \mu$ l of lysate was transferred into a single $2 \mathrm{ml}$ tube giving a total of $1 \mathrm{ml}$ lysate from 40 bees. The tube was incubated at $65^{\circ} \mathrm{C}$ for a further 10 minutes with mixing every two minutes and then centrifuged for 10 minutes at $15,000 \times x$. Once centrifuged, $700 \mu l$ of supernatant was 
pipetted off and transferred to a new tube, containing $700 \mu$ l of Chlorofom: Isoamyl Alcohol (Sigma-Aldrich, 24:1). The tube was vortexed to mix well and centrifuged for 5 minutes at $15,000 \times$ g. $500 \mu l$ of the top phase was then transferred to a new tube containing $350 \mu \mathrm{l}$ of Isopropanol (Scharlau, 2-Propanol), the tube was then inverted several times and centrifuged for 10 minutes at 15,000xg. Supernatant was removed from the tube, without disturbing the DNA pellet and $300 \mu$ l 70\% Ethanol added (Scharlau, absolute Ethanol) the tube was then vortexed and centrifuged for 5 minutes at 15,000xg. Ethanol was removed by pipette and pellet left to dry for 10 minutes, allowing any remaining ethanol to evaporate. DNA pellets that appeared dark in colour were cleaned using the CLEAN ${ }^{\top M}$ system (dnature). Clean DNA pellets had $100 \mu$ l of Elution Buffer (Geneaid, Taiwan) added and were left to dissolve for 30 minutes prior to real-time PCR. After testing samples were archived at $-20^{\circ} \mathrm{C}$.

\section{Primer Selection}

The primer sequences published by Runckel et al., (2011) were used to detect the two trypanosomes C. mellificae and L. passim (qCrFwd1: 5'-TCCACTCTGCAAACGATGAC-3', qCrRev1: 5'-GGGCCGAATGGAAAAGATAC-3'). In addition, a commercial real-time PCR Trypanosome Kit containing primers designed by dnature was used. The hydrolysis probe in the kits anneals only to the target gene once it has been amplified, thus adding an additional level of specificity to the test.

A real-time PCR with a primer specific to C. mellificae was published by Stevanovic et al., (2016), (Cm_cytF: 5'- AGTTTGAGCTGTTGGATTTGTT-3', Cm_cytR: 5'AACCTATTACAGGCACAGTTGC-3') this was used to identify $C$. mellificae in samples.

Commercially available kits were used to identify the presence of the two Nosema spp. The Nosema apis and Nosema ceranae real-time PCR kits (dnature) contain primers and a hydrolysis probe which gives greater specificity to the test. The reference gene $\beta$-actin was used in these real-time PCR assays of DNA in the RNA virus assays for DWV the reference gene was RP-S5. 


\section{Real-time PCR}

Real-time PCR reactions with qCrFwd1/Rev1 primer pairs were performed in $10 \mu \mathrm{l}$ volumes containing 2.7 $\mu$ l of PCR Grade Water (Solis Bio-Dyne, Estonia), $0.3 \mu$ l of combined forward and reverse primers at $10 \mu \mathrm{M}, 5 \mu \mathrm{l}$ PerfeCTa SYBR Green Fastmix (Quantabio, Beverley, USA), and $2 \mu \mathrm{l}$ of template DNA at a 1:10 dilution, this reduces inhibition which was observed in neat samples. Cycling conditions were set at $95^{\circ} \mathrm{C}$ for 3 minutes followed by 45 cycles at $95^{\circ} \mathrm{C}$ for 5 seconds and $60^{\circ} \mathrm{C}$ for 20 seconds. Real-time PCR reactions with the Trypanosome Kit (dnature) were performed in $10 \mu$ l volumes containing $0.5 \mu \mathrm{l}$ of $20 \mathrm{X}$ Trypanosome oligo mix, $2.5 \mu \mathrm{l}$ of PCR Grade Water (Solis Bio-Dyne), $5 \mu \mathrm{l}$ Master Mix, and $2 \mu \mathrm{l}$ of neat template DNA. Cycling conditions were $95^{\circ} \mathrm{C}$ for 3 minutes followed by 45 cycles at $95^{\circ} \mathrm{C}$ for 5 seconds and $60^{\circ} \mathrm{C}$ for 20 seconds. Real-time PCR reactions with Cm_cytF/R primer pairs were performed in $10 \mu \mathrm{l}$ volumes containing $2.8 \mu \mathrm{l}$ of PCR Grade Water (Solis Bio-Dyne), $0.2 \mu \mathrm{l}$ of combined forward and reverse primers at $10 \mu \mathrm{M}, 5 \mu \mathrm{l}$ PerfeCTa SYBR Green Fastmix (Quantabio), and $2 \mu \mathrm{l}$ of template DNA at a 1:10 dilution. Cycling conditions were $95^{\circ} \mathrm{C}$ for 3 minutes followed by 45 cycles at $95^{\circ} \mathrm{C}$ for 5 seconds and $62^{\circ} \mathrm{C}$ for 20 seconds. All real-time PCR reactions were performed using the Eco Real-Time PCR System (Illumina, California, USA) and included the reference gene $\beta$-actin (Cornman et al., 2012; Evans et al., 2013; Tritschler et al., 2017).

Real-time PCR Cq values of $>38$ are, for this study regarded as not detected. This value was arrived at based on the standard curves lowest detectable Cq reading. This level was used in an attempt to ensure inclusion of lowest detectable levels of the target gene and exclusion of low-level non-target gene amplification (Bustin et al., 2009).

\section{Sequencing}

Primers from unpublished work by B Dainat, tested and published by Tritshler et al., (2017) were adapted (changes shown in bold) to detect GAPDH sequences in the trypanosomes species C. mellificae, C. expoeki, C. bombi and L.passim (Trypan_GAPDH-F: 5'GTGCTBGTGGTGAACGGCCA-3', Trypan_GAPDH-R: 5'-GTCCTTGAKSGACACGCCGT-3') and yield 360bp amplicons. Real-time PCR reactions with the primer pairs Trypan_GAPDH were 
performed in $10 \mu \mathrm{l}$ volumes containing $2.7 \mu \mathrm{l}$ of PCR Grade Water (Solis Bio-Dyne), $0.3 \mu \mathrm{l}$ of combined forward and reverse primers at $10 \mu \mathrm{M}, 5 \mu \mathrm{l}$ PerfeCTa SYBR Green Fastmix (Quantabio), and $2 \mu \mathrm{l}$ of template DNA at a $1: 10$ dilution. Cycling conditions were $95^{\circ} \mathrm{C}$ for 3 minutes followed by 45 cycles at $95^{\circ} \mathrm{C}$ for 5 seconds and $62^{\circ} \mathrm{C}$ for 20 seconds. Amplified real-time PCR products were sent for Sanger sequencing (Lincoln Bio-Protection, New Zealand).

Sequenced amplicons containing 260bp were analysed using MEGA7 (www.megasoftware.net). This tool was used to align sequences and create a phylogenetic tree. First sequenced were entered and aligned by ClustalW, the alignments are then visually checked. Once aligned MEGA7 determines the best model for the phylogenetic analyses based on the sequences you are analysing. The best model is used to help construct a maximum likelihood tree, which includes 1000 bootstrap analyses to estimate the reliability of the phylogenetic tree. The tree will then show the evolutionary relationships among samples from this study and those sequences already deposited in GenBank (https://www.ncbi.nlm.nih.gov/genbank/).

\section{Data Analyses}

The 47 samples received were mapped using GPS coordinates in the R Statistical Package R Core Team (2015). The percentage of New Zealand sites infected by a pathogen was calculated by taking the number of positive sites divided by the total number of sites tested, 47, and multiplied by 100 .

In addition to the overview a yearlong study to determine if the trypanosome infection level, or trypanosome species diversity were to change over time. This was achieved by analysing several colonies in a yearlong study using Performance-Analytics package (Peterson et al., 2014) in the R Statistical Package R Core Team (2015).

Yearlong Study of Bee Pathogens 
Of the beekeepers who provided samples for the overview on 11 November 2016, appropriate sites for a yearlong study were selected. Selection was based firstly on location, to ensure there would be a good distribution of sites across New Zealand. A second selection requirement was the beekeeper's commitment to provide samples every five weeks, from the same hive, for the entirety of the project. Any beekeeper who could not commit was excluded. From these selection requirements fifteen sites were identified and confirmed as sample sites for the year project (Appendix Two).

Samples were taken at intervals of approximately 5 weeks (Table 1 ) from the same hive. In addition, beekeepers completed a submission form providing data on the hive including any treatments, feedings and movements.

Table 1 Collection Dates

Dates of collection of honey bees for the study from December 2016 - November 2017

\begin{tabular}{|l|l|l|}
\hline Collection \#1 & 5-9 December 2016 & \multirow{2}{*}{ Summer } \\
\cline { 1 - 2 } Collection \#2 & 16-20 January 2017 & \multirow{2}{*}{ Autumn } \\
\cline { 1 - 2 } Collection \#3 & 27 February - 3 March 2017 & \\
\hline Collection \#4 & 10-14 April 2017 & \multirow{2}{*}{ Winter } \\
\cline { 1 - 2 } Collection \#5 & 22-26 May 2017 & \multirow{2}{*}{ Spring } \\
\cline { 1 - 2 } Collection \#6 & 3-7 July 2017 & \\
\hline Collection \#7 & 14-18 August 2017 \\
\cline { 1 - 2 } Collection \#8 & 25-29 September 2017 & \\
\cline { 1 - 2 } Collection \#9 & 6-10 November 2017 & \\
\hline
\end{tabular}

\section{Primer selection for DWV}

Standard curves were generated as above, for DWV and for this RNA virus I used the reference gene RP-S5 (Wheeler et al., 2006). Primer sequences published by Chantawannakul (2006) were used to identify the virus in this study (DWV958F: 5'CCTGGACAAGGTCTCGGTAGAA-3', DWV9711R 5'-ATTCAGGACCCCACCCAAAT-3', DWV9627T: 5'-CATGCTCGAGGATTGGGTCGTCGT-3'). The sequences can detect all three classes of DWV as per Mordecai et al., (2016). 


\section{Real-time PCR of DWV}

Real-time RT-PCR reactions with the DWV958F/9711R primers were performed in $10 \mu \mathrm{l}$ volumes containing $4.95 \mu \mathrm{l}$ of PCR Grade Water (Solis Bio-Dyne), $0.4 \mu \mathrm{l}$ of combined forward and reverse primers at $10 \mu \mathrm{M}, 0.15 \mu \mathrm{l}$ probe at $10 \mu \mathrm{M}, 2.5 \mu \mathrm{l}$ Ultraplex 1-Step ToughMix (Quanta-Bio) and $2 \mu \mathrm{l}$ of template DNA. Cycling conditions were $50^{\circ} \mathrm{C}$ for 10 minutes to begin first strand cDNA synthesis, followed by $95^{\circ} \mathrm{C}$ for 3 minutes to deactivate the reverse transcription and activate the hot start. The incubation was followed by 45 cycles of $95^{\circ} \mathrm{C}$ for 5 seconds and $60^{\circ} \mathrm{C}$ for 20 . All real-time PCR reactions were performed using the Eco Real-Time PCR System (IIlumina, California, USA) and included the reference gene RP-S5 (Wheeler et al., 2006) (RPS5Fwd: 5'-AATTATTTGGTCGCTGGAATTG-3', RPS5Rev: 5'TAACGTCCAGCAGAATGTGGTA-3').

\section{Data Analyses}

The prevalence of pathogens over time and season was calculated using Microsoft Excel 365 (2017) by dividing the number of site infected by the total number of sites sampled from. This data was then visualized graphically using the R Statistical Package (2009). Statistical analyses of the prevalence data included binomial analyses of the presence or absence of pathogens to determine any significant changes occurring across the year. In addition, a general linearised mixed model (GLMM) with fixed effects being the pathogen L. passim, as this was the most prevalent species, and fixed season being summer as this was the first sampling season. The GLMM considered random measures of site and presence of other pathogens/seasons in relation to the fixed effects. A Tukey test on the GLMM was used to identify any differences between pathogen infections (Hothorn et al., 2008). All was supported by repeated measure ANOVA to discover if a relationship exists between any of the variables in the data. 


\section{Results}

The overview study was to determine if the trypanosomes C. mellificae and L. passim are in New Zealand honey bees and examine their genetic diversity. Site samples were tested to determine if also infected with the two Nosema spp. and DWV.

\section{Overview}

Identification and Distribution of Trypanosomes in New Zealand

All 47 honey bee samples collected on 11 November 2016 were tested for the presence of trypanosomes, the real-time PCR results showed that 46 of the 47 samples (98\%) were positive for trypanosomes. The map in Figure 1 clearly identifying a single site in the South Island that returned a not detected real-time PCR result. The reference gene $\beta$-actin was used to normalise results and were detected in every sample tested excluding the no template control (NTC).

Identification of the Trypanosomes C. mellificae and L. passim

The 47 samples underwent a real-time PCR test using the $\mathrm{Cm}$ _cytF/R primer pairs. These published primers by Stevanovic et al. (2016) were reported as being specific to C. mellificae. This primer set $\mathrm{Cm}$ _cytF/R did not detect C. mellificae in any of these 47 samples. Unfortunately, we had no sample that could be used as a positive control, as the importation of $C$. mellificae or synthesis of a control was cost prohibitive.

Of the trypanosome positive samples, twenty-five were amplified for sequencing (BioProtection, Lincoln University, New Zealand) using the primers Trypan_GAPDH F/R that were adapted (see Methods) for this study and yield 360bp amplicons. Sequences obtained were identified by BLASTn searches of the NCBI (GenBank) which confirmed a 99-100\% shared identity to the L. passim sequences available. Comparison of sequences to the C. mellificae ATCC30254 (KJ704281) culture strain from Langridge and McGhee (1967) showed only a $94 \%$ shared identity. 


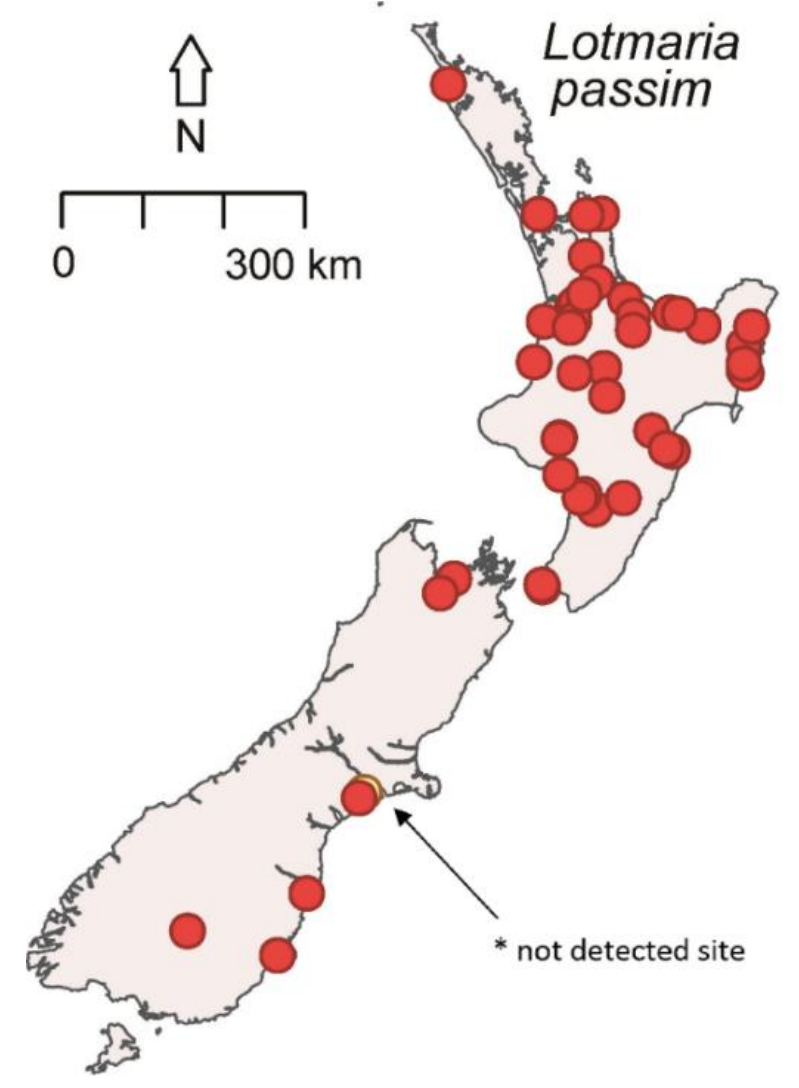

Figure 1 Trypanosome distribution across New Zealand.

Real-time PCR for trypanosomes detection showed 46 positives in red and one negative or not-detected sample in yellow.

Phylogenetic analysis of the sequences was completed using MEGA7 (Kumar et al., 2016), adapted Trypan_GAPDH sequences were manually checked and aligned by ClustalW. Additional sequences of closely related $L$. passim species were downloaded from GenBank (KM066224, KJ712256, AB716359, KX953209) to compare with the New Zealand samples of L. passim. Limited sequences are available for L. passim identification on GenBank, likely due to the new identification of the species and few studies conducted to date. Additional sequences from the $C$. mellificae culture strain ATCC30254 (KJ704281) from Langridge and McGhee (1967) were also downloaded along with the accessions for C. expoeki (KY129955), C. bombi (GU321192), and Leptomonas spp. (KP717896) to provide an example of the differences between these species and those identified in this study. A maximum likelihood 
phylogenetic tree was generated by the Neighbour-joining model, as shown in Figure 2, these data was supported by 1,000 bootstrap replicates.

Samples from this study are in blue. Analysis of the New Zealand sequences identified two genotypes in New Zealand. These genotypes show only one variable site which contains a single $(A-C)$ nucleotide substitution. The phylogenetic tree in Figure 2 does not demonstrate any variation, this is likely because the sequence variation is so small. The single sample with the variation is identified with a red asterisk. The samples closest genetic matches are with L. passim genotypes from Europe, Japan, the United States, and South America. With $96 \%$ bootstrap support of the genetic relationship. Sequences for $L$. passim identified in this study will be lodged with GenBank.

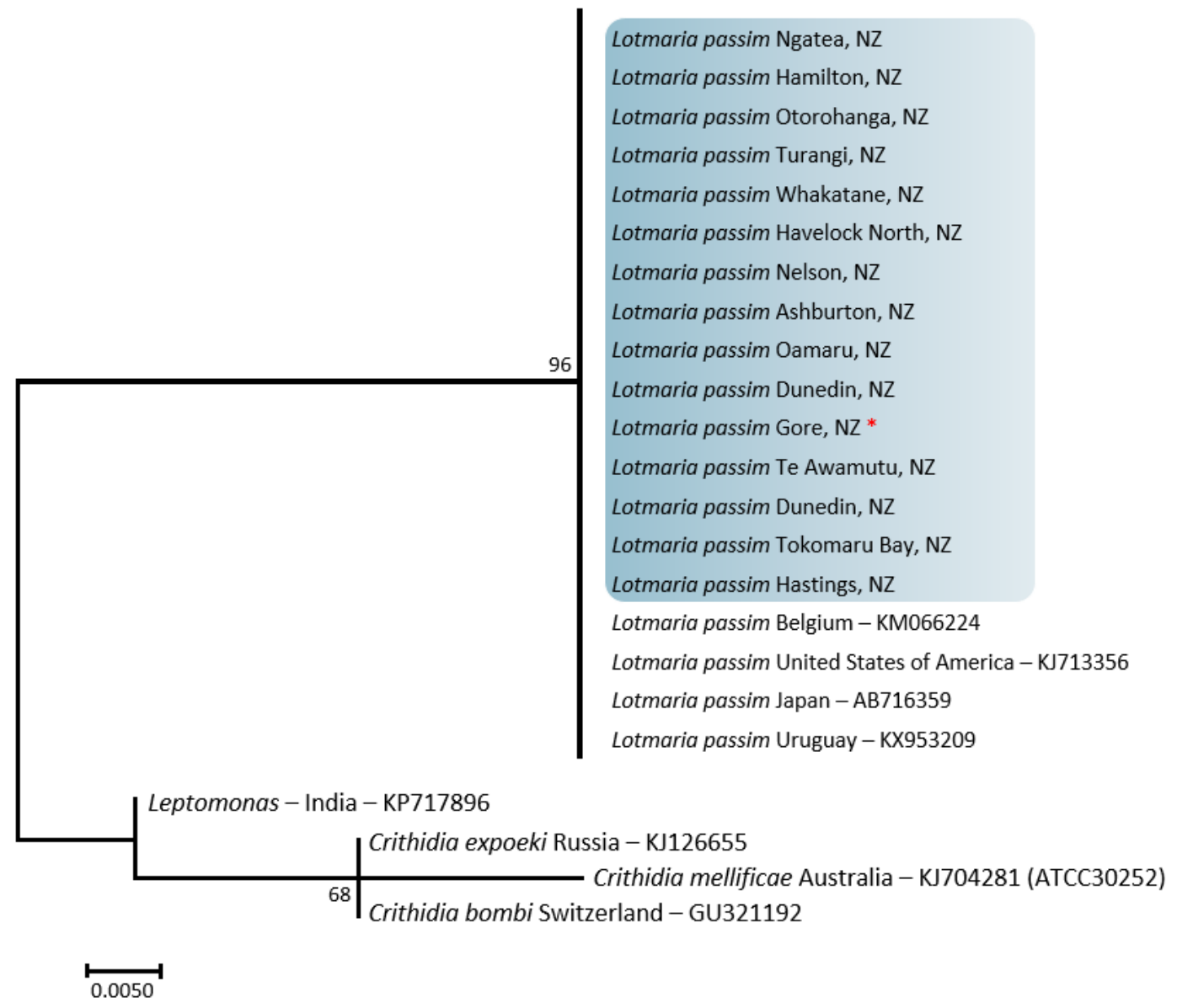

Figure 2 Molecular Phylogenetic analysis by Maximum Likelihood method

The evolutionary history was inferred by using the Maximum Likelihood method based on the Jukes-Cantor model (Jukes and Cantor, 1969). The tree is drawn to scale, with branch lengths measured in the number of substitutions per site. The analysis involved 22 nucleotide sequences. Codon positions included were $1 s t+2 n d+3 r d+N o n c o d i n g$. All positions containing gaps and missing data were eliminated. There was a total of 66 positions in the final dataset. Evolutionary analyses were conducted in MEGA7 (Kumar et al., 2016). 
There is little genetic diversity in the sequences of this study, it is likely therefore that L. passim was introduced through one or all these sources (Europe, USA, South America) or another country where it has yet to be identified.

\section{Distribution of pathogens N. apis, N. ceranae and DWV}

Across New Zealand L. passim was the most prevalent pathogen. In addition to trypanosomes, the 47 samples collected were tested for N.apis, N. ceranae, and DWV using real-time PCR. The distribution of these pathogens across New Zealand is shown in the maps in Figure 3. Across the 47 sites in New Zealand N. apis was the most prevalent, after L. passim, being found in 43 of 47 samples (92\%) and well distributed across New Zealand. In comparison $N$. ceranae was the least prevalent pathogen detected in this study with positive results in only 21 of 47 samples (45\%). It is of interest that the 21 positive samples were only found in the North Island samples from this study. Finally, DWV was found in 32 of 47 samples (68\%) and was present in both Islands. The reference gene $\beta$ actin was used to normalise results for trypanosomes and Nosema spp. and RP-S5 for DWV, these were detected in every sample tested excluding the no template control (NTC).

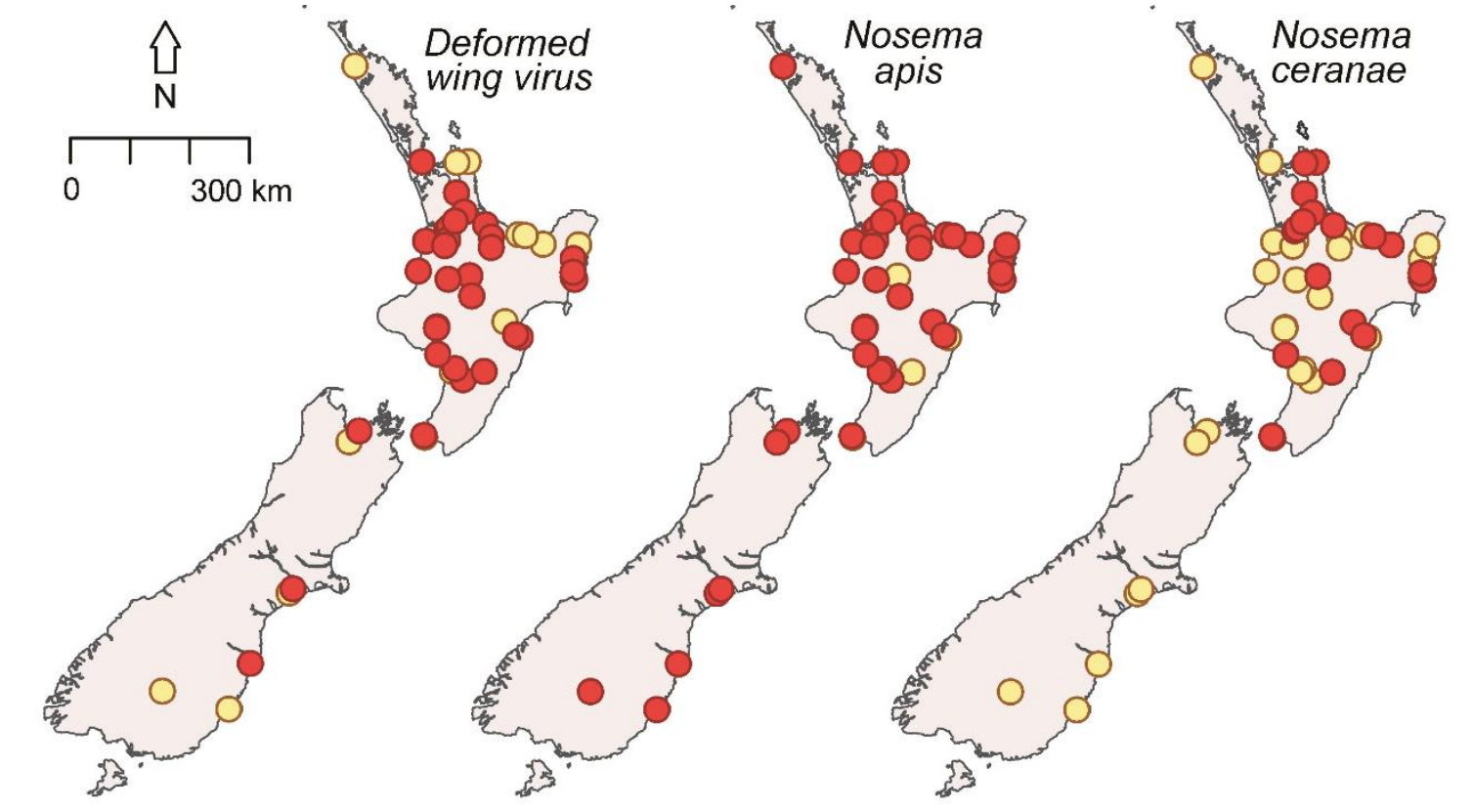

Figure 3 Distribution of other pathogens in New Zealand

Positives shown in red, negative in yellow the most prevalent pathogen shown is $N$. apis $92 \%$, second is DWV $68 \%$ and third is $N$. ceranae with $45 \%$ detection and positive samples in this study only being detected only in the North Island. 


\section{Population dynamics of L. passim, two Nosema spp. and DWV}

This study sampling was taken over a year from December 2016 - November 2017 to determine if trypanosome infection level, or trypanosome species diversity, would change over time. In this study a total of nine samples from each of the 15 sites selected for the temporal study were collected over the year. Of the selected sites, 13 of 15 colonies survived the year, with two colonies being lost during the study. The hive losses both occurred in the central New Zealand region. The first hive was described by the beekeeper as a hive with a heavy Varroa mite levels despite several treatments in February the hive was found with no bees, honey stores in place and Varroa mites present in capped brood which had chilled. The last sample collected from this hive was 27 February - 3 March 2017. The second hive loss was described by the beekeeper as having a small number of bees, evidence of the hive being 'robbed out' indicating an overall weakened hive. The last sample collected for this hive was during 22-26 May 2017. Data from these colonies were included in this study totalling 125 samples collected during the year. Each sample was tested for trypanosomes and the three other pathogens of interest.

\section{Hive Treatments}

Throughout the year study beekeepers recorded feeding and Varroa treatments, if any, for the hive that was being sampled. While there are were no correlations attempted here between pathogen prevalence and Varroa treatments, beekeepers are applying Varroa treatments predominantly in autumn/spring. Further information on when treatments/feed applications in the hive are included in Appendix Two.

To determine the dynamics of pathogens over time, each site was classified as either infected or not infected. Prevalence was calculated for each season by comparing the infected colonies to the total colonies sampled at each collection date outline previously (Table 1). The prevalence of L. passim, the two Nosema spp. and DWV shown in Figure 4. The high prevalence of L. passim throughout the year makes it the most frequently detected of the pathogens examined. Prevalence of $100 \%$ was demonstrated at each 
collection point from December 2016 to July 2017, L. passim shows infection all year round with reduction detected in spring, however, this reduction is small possibly due to error.

Of the two Nosema spp. tested N. apis was the most prevalent throughout the year, reflecting the widespread distribution of $N$. apis across New Zealand as shown in the overview maps in Figure 3. While there was variation between sites across the sampling periods there appeared to have been an overall increase of Nosema in prevalence during spring. Three sites on the East Coast of the North Island showed the lowest overall prevalence of Nosema in the samples taken in this study. There was a marked difference in $N$. ceranae prevalence, with it being the lowest of all pathogens examined in this study (Figure 4). Highest infection levels occurred during November and the lowest in JulyAugust, mid-winter, these results could be confirmed with additional testing. The South Island samples no longer remain uninfected with $N$. ceranae, which was detected in two samples colonies in Christchurch and Dunedin.

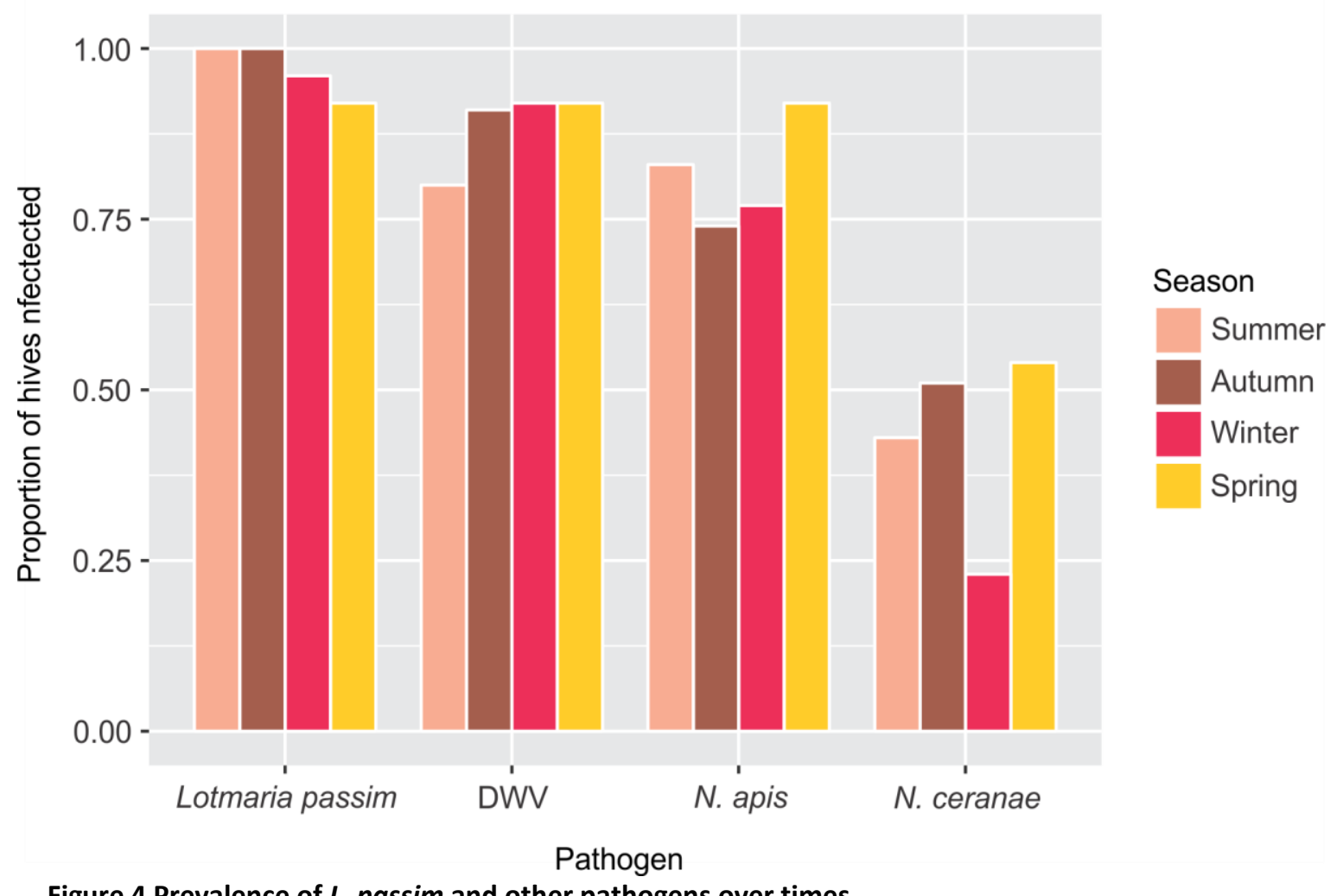

Figure 4 Prevalence of $L$. passim and other pathogens over times.

The prevalence of $L$. passim overtime shows sites with consistently high prevalence with a drop-in spring. DWV levels indicate this was the second most prevalent followed by $N$. apis and $N$. ceranae being the least prevalent in this study 
DWV was the second most prevalent pathogen to L. passim, though there was substantial variation in DWV levels over the year. Indicating no specific peak prevalence in abundance. Since DWV infection is closely related to infection by the Varroa mite, the abundance of the parasite may be a factor in the variation of DWV levels over time and within colonies.

A binomial (presence/absence) analysis was completed using the Ime4 package (Bates et al., 2015) within the R Statistical Package (2009) to run a generalised linear mix model (GLMM) which takes into account random effects. The site was used as the random effect and months were nested within season as a repeated measure factor. The full model lacked significant interaction terms $(p>0.984)$, therefore the interaction terms were removed from the analysis.

For the final binomial model, the most abundant pathogen of L. passim was used as the reference pathogen and the seasonal reference category was summer, when the first samples were taken. All other pathogens were significantly less prevalent than L. passim $(p<0.043 ;$ Table 2). A pairwise analysis of prevalence between pathogens, was completed using a Tukey test (Table 3) (Hothorn et al., 2008) which largely confirmed patterns observed in Figure 4. For example, N. ceranae were significantly less prevalent than L. passim $(p<0.001)$. DWV showed a similar prevalence to N. apis $(p=0.310$; Table 3$)$

Table 2 Results from GLMM using Ime4 package

The random effects used were the sites, and the reference category for pathogens was $L$. passim and all other pathogens were less prevalent than this. The reference category for season was summer with no significance significant in other seasons.

\begin{tabular}{|l|c|c|c|c|}
\hline \multicolumn{5}{|l|}{ Lotmaria passim } \\
\hline Variable & Estimate & Std. Error & Z value & p-value \\
\hline (Intercept) & 3.890 & 0.663 & 5.865 & $<0.001^{* * *}$ \\
\hline N. ceranae & -4.255 & 0.630 & -6.759 & $<0.001^{* * *}$ \\
\hline N. apis & -2.337 & 0.634 & -3.688 & $0.001^{* *}$ \\
\hline DWV & -1.695 & 0.653 & -2.595 & $0.0432^{*}$ \\
\hline Autumn & 0.253 & 0.439 & 0.576 & 0.565 \\
\hline Winter & -0.401 & 0.432 & -0.928 & 0.353 \\
\hline Spring & 0.573 & 0.460 & 1.244 & 0.214 \\
\hline
\end{tabular}


Table 3 Tukey Test Results

Comparisons with greatest significance are marked $* * * N$. ceranae $(-4.225)$ is much less abundant than L. passim, N. apis (1.918) and DWV (2.560) are both more abundant than $N$. ceranae. There is no seasonal significance identified.

\begin{tabular}{|l|c|c|c|c|}
\hline \multicolumn{5}{|l|}{ Pathogen Comparison } \\
\hline & Estimate & Std. Error & Z value & p-value \\
\hline N. ceranae-L. passim & -4.255 & 0.630 & -6.759 & $<0.001^{* * *}$ \\
\hline N. apis - L. passim & -2.337 & 0.634 & -3.688 & $0.001^{* *}$ \\
\hline DWV - L. passim & -1.695 & 0.653 & -2.595 & $0.0432^{*}$ \\
\hline N. apis - N. ceranae & 1.918 & 0.320 & 5.992 & $<0.001^{* * *}$ \\
\hline DWV - N. ceranae & 2.560 & 0.364 & 7.028 & $<0.001^{* * *}$ \\
\hline DWV - N. apis & 0.642 & 0.378 & 1.700 & 0.310 \\
\hline Seasonal Comparison & \multicolumn{5}{|l}{} \\
\hline Summer - Autumn & 0.253 & 0.439 & 0.576 & 0.565 \\
\hline Summer - Winter & -0.401 & 0.432 & -0.928 & 0.353 \\
\hline Summer - Spring & 0.573 & 0.460 & 1.244 & 0.214 \\
\hline
\end{tabular}

\section{Pathogen Population Dynamics}

Further analysis was undertaken to determine pathogen abundance and dynamics over the period December 2016 - November 2017 from a sample of 15 colonies. For analysis, samples were sorted into regions of New Zealand based on GPS locations. Five located in top of the North Island "Northern Sites", five in central regions of the North Island "Central Sites" and 5 in lower North and South Islands "Southern Sites". Of these different regions six examples, with two from each region, are shown in Figure 5. These data confirm high levels of $L$. passim infection across New Zealand with some variations across the year which should be confirmed with more study. 

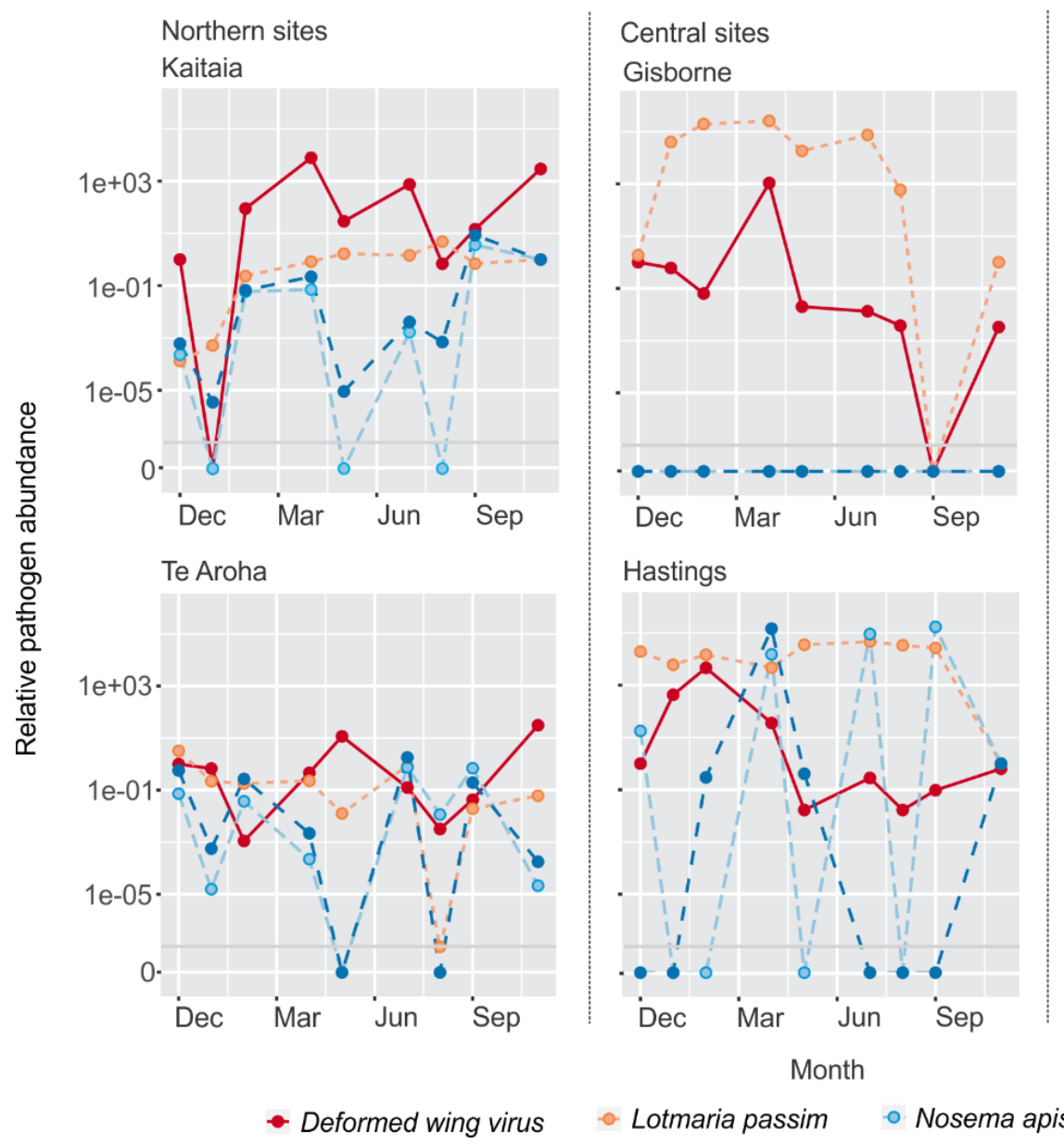

Southern sites

Christchurch

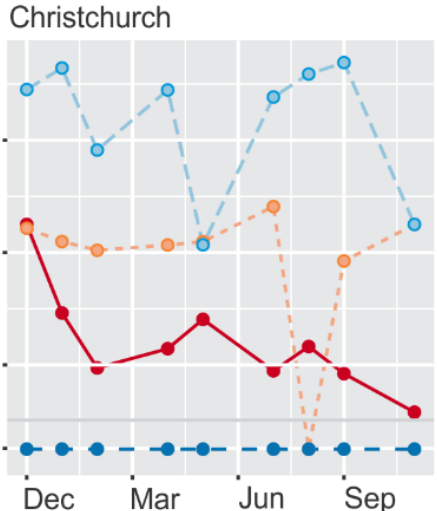

Dunedin

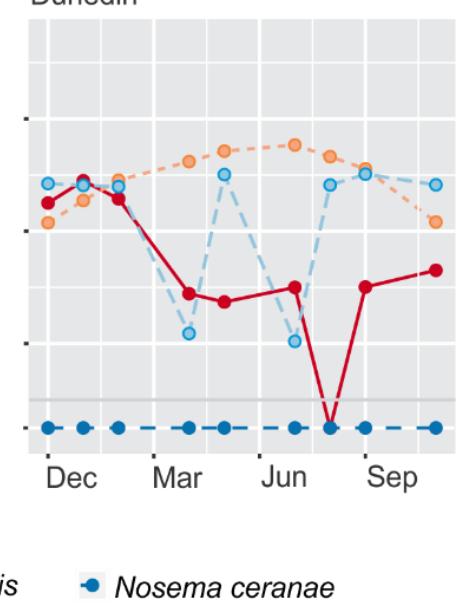

Figure 5 Relative abundance of four pathogens in three New Zealand regions

Six samples sites, two from each region have relative abundance of pathogens plotted over time on a log graph. The most abundant $L$. passim is found in all samples along with $N$. apis and DWV. There is an absence of $N$. ceranae in the Southern sites and in Gisborne

The relative abundance levels of the two Nosema spp. showed similar, although highly variable trends, in these sites throughout the year; where the two species are present together. There was an absence of the otherwise prevalent N. apis in the Gisborne site. However, this pathogen was most abundant in the Christchurch sample. The absence of N. ceranae from Southern sites is shown, however, there were very low levels detected in the Dunedin (not shown in the site examples used in Figure 5). The variation in abundance of both Nosema spp. was demonstrated by no identifiable peaks or lows across the year. The variability of DWV over the year is evident in these sites, any peaks or low are not consistent. 
Table 4 Results from repeated measures ANOVA on log-transformed pathogen abundances over time. Region refers to the 15 sites, which were split into three groups of 5 sites each based on their latitude (a south, central and north set of sites). Time is the repeated measures factor, Region $\times$ Time is the interaction. The model used was a mixed effects model, using site as a random factor. The model used is that based on Mangiafico,(2016) using the Ime4 (Pinheiro et al., 2016) and car (Fox and Weisberg, 2011) packages in R. There were no significant main effects or interactions for any of the pathogens $(p<0.05)$, likely due to the substantial amount of variation in pathogen abundance within and between sites.

\begin{tabular}{|l|c|c|c|}
\hline Nosema ceranae & d.f. & F-value & p-value \\
\hline Variable & $1(107)$ & 6.0425 & 0.0156 \\
\hline (Intercept) & $2(12)$ & 0.7461 & 0.4950 \\
\hline Region & $1(107)$ & 0.0648 & 0.7995 \\
\hline Time & $2(107)$ & 0.2529 & 0.7770 \\
\hline Region $\times$ time & F-value & p-value \\
\hline Lotmaria passim & d.f. & 0.0001 \\
\hline Variable & $1(107)$ & 17.1177 & 0.0741 \\
\hline (Intercept) & $2(12)$ & 3.2581 & 0.2731 \\
\hline Region & $1(107)$ & 1.2133 & 0.7377 \\
\hline Time & $2(107)$ & 0.3051 & $p$-value \\
\hline Region $\times$ time & d.f. & F-value & 0.0023 \\
\hline DWV & $1(107)$ & 9.7779 & 0.9256 \\
\hline Variable & $2(12)$ & 0.0778 & 0.8051 \\
\hline (Intercept) & $1(107)$ & 0.0612 & 0.2909 \\
\hline Region & $2(107)$ & 1.2492 & $p$-value \\
\hline Time & d.f. & F-value & 0.0013 \\
\hline Region $\times$ time & $1(107)$ & 10.8762 & 0.0652 \\
\hline Nosema apis & $2(12)$ & 3.4566 & 0.1851 \\
\hline Variable & $1(107)$ & 1.7787 & 0.5501 \\
\hline (Intercept) & $2(107)$ & 0.6010 & \\
\hline Region & \multicolumn{3}{|l|}{} \\
\hline Time & \multicolumn{3}{|l|}{} \\
\hline Region $\times$ time & \multicolumn{3}{|l|}{} \\
\hline
\end{tabular}

The ANOVA analyses with time as the repeated measure factor and Region $\mathrm{x}$ is the interaction shown in Table 4. This analysis indicates that patterns of abundance of pathogens over time did not change between regions in this study $(p \geq 0.185)$. The high levels of variation within and between sites, even within regions (eg: Figure 6), likely contributed to this result.

The data was further analysed to investigate correlations between pathogens, using the Performance Analytics package (Peterson et al. (2014) R Core Team (2015)). The analyses used a Spearman's correlation coefficient, which is a rank-based analysis as the data were 
clearly not normally distributed. In an analysis of all samples ( $n=125)$, only one correlation between pathogens was statistically significant $(p<0.05)$ which was the relationship between DWV and N. ceranae (Figure 6(a)).

Given the results that demonstrated the frequent absence of the pathogen $N$. ceranae in the South Island, a second set of analyses were undertaken where only samples in which all pathogens $(n=30)$ were present have been included (Figure $6(b))$. This analysis excluded the substantial influence of 0 values on rank correlations and may give a better insight on the influence of each pathogen on the abundance of other pathogens. This analysis may give a better representation of the potential of pathogen correlations. Four of the six analyses using this approach were statistically significant, with all showing positive correlations. The highest correlation coefficient was $0.93(p<0.001)$ and indicate that as $N$. apis increased, the prevalence of $N$. ceranae also increased (or vice-versa) we would need additional experimental work to determine specifically how each pathogen influences the other. 
(a) All data $(n=125)$

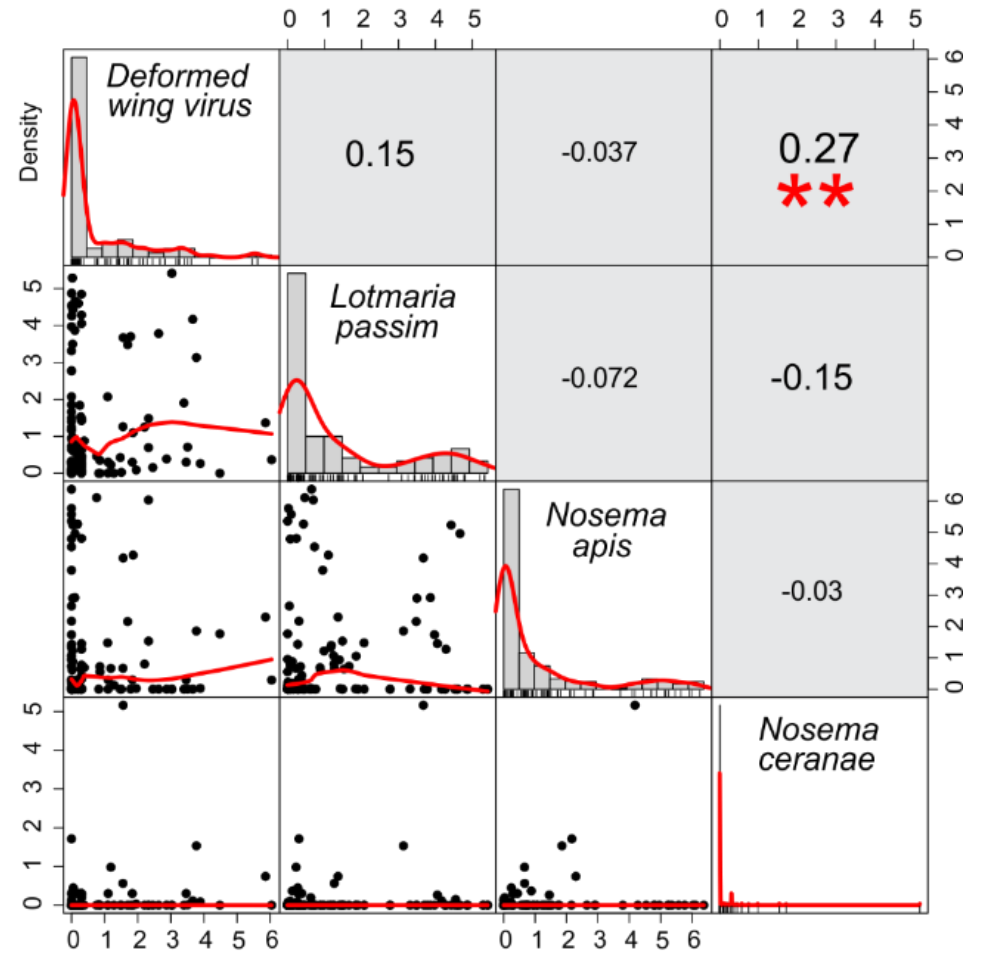

(b) Only samples with all four pathogens present $(n=30)$

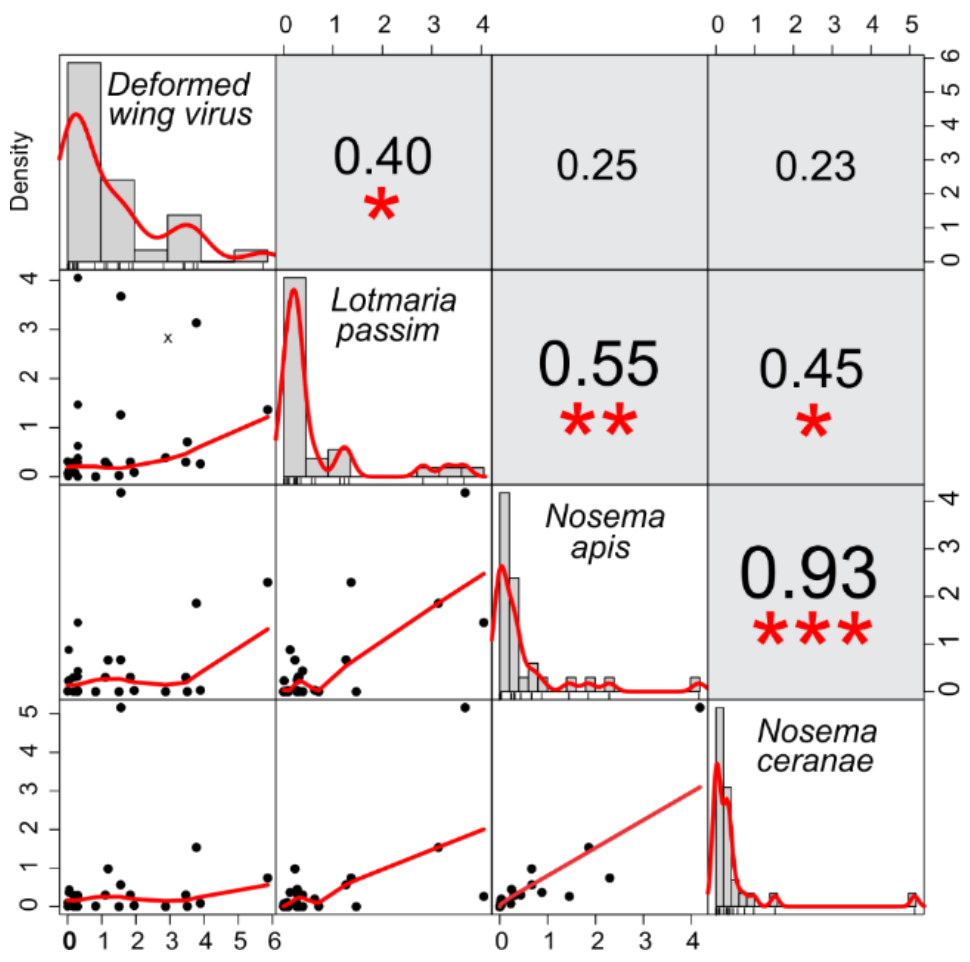

Figure 6 Spearman's coefficients data

(a)Coefficients show very little correlation between pathogens and only one incidence of significance between DWV and $N$. ceranae. (b) excluding samples which were not positive for all pathogens shows positive correlations between L. passim and Nosema spp. as well as a strong positive correlation between Nosema spp. ${ }^{*}=(p<0.05)^{* *}=(p$ $<0.01)^{* * *}=(p<0.001) .1^{*}$ is significant to $(p<0.05), 2^{* *}(p<0.01)$ and $3^{* * *}(p<0.001)$ 


\section{Discussion}

\section{Trypanosomes in New Zealand}

Honey bee colony losses occur throughout New Zealand every year. With honey being a major export of New Zealand and bees being vital to pollination, investigation into the causes of colony loss is of great value to apicultural and primary industries. Trypanosomes infecting honey bees have recently begun to be studied, however the distribution and effect of this pathogen remains largely unknown. This study first provided an overview of the distribution of trypanosomes and other pathogens in New Zealand. This overview is followed up by a temporal study following the population dynamics of trypanosomes in addition to other pathogens in New Zealand honey bees.

The 47 samples collected in November 2016 provides a valuable data set from which to start analyses of trypanosomes in New Zealand. Due to the geographical proximity of New Zealand to Australia it was expected that $C$. mellificae would be present here and be most similar to that which was first identified in Australia by Langridge and McGhee (1967). This study did not detect $C$. mellificae in New Zealand. It is however possible that $C$. mellificae is present here, in low undetectable levels, or at sites unsampled in my survey. Studies into trypanosomes in Belgium in 2015 showed that $C$. mellificae, when identified, was found at low levels (Ravoet et al., 2015). This is a possible explanation for C. mellificae being undetected in New Zealand as it has been undetected in study samples from Switzerland, Chile, Japan and Serbia (Arismendi et al., 2016; Tritschler et al., 2017; Vejnovic et al., 2017). Furthermore, if the species C. mellificae is only found in low levels could this indicate that,

not only is L. passim the predominant trypanosome but that it may be replacing or outcompeting $C$. mellificae. Both trypanosomes reside in the hindgut of honey bees and as such may compete for resources (Schwarz et al., 2015). Trypanosome detection by molecular methods has developed over the last 5 years however, these species may have been present in honey bees for a lot longer. 
Detection of $L$. passim was by real-time PCR, of the 47 samples collected 46 samples were positive for L. passim (98\%). A single sample from Christchurch did not detect L. passim. Genetic variation across samples was expected, as 39 different beekeepers were collecting for this overview, with assistance by myself. Results, however, showed consistent high levels of L. passim across New Zealand with the greatest infection being found in Whakatane and the lowest in a Gisborne sample. The ubiquitous distribution of L. passim amongst New Zealand honey bee colonies certainly supports the etymology of the species name passim meaning "everywhere" with regards to distribution within honey bees. Yet L. passim has not been detected in other species of bees and more research should be undertaken to identify other trypanosome hosts.

The uniform distribution of L. passim indicates that it is likely to have been present in New Zealand honey bees for some time. A review of historic samples, if available, could isolate exactly when L. passim arrived and if there has ever been detectable levels of $C$. mellificae in New Zealand. There may be some samples available for such a historic analysis, including samples submitted and stored for the American Foulbrood programme in New Zealand. Development of more specific molecular methods of detection would also allow detection of trypanosomes at lower concentration levels. For example a recently published real-time PCR test by Xu et al. (2018), a triplex real-time PCR test based on the qCrFwd1/Rev1 primers used in this study with the addition of a minor groove binding probe (MGB), for even greater specificity.

The ability to detect both C. mellificae and L. passim simultaneously in addition to an internal control could give a faster evaluation of affected colonies (Xu et al., 2018). However, the efficiency of the real-time PCR test was slightly low at $90 \%$, which may result in small levels of $C$. mellificae being missed during amplification.

The phylogenetic analysis was undertaken using adapted GAPDH primers from Tritschler et al. (2017). GenBank GAPDH accessions for C. mellificae, C. bombi, C. expoeki and L. passim GAPDH sequences were aligned using Multalin (www.multalin.toulouse.inra.fr/multalin/) then compared with the published GAPDH primers. Two degenerate base pair changes 
were made to the primers to ensure the inclusion of all species, if present, in the samples. The analysis showed that the L. passim species in New Zealand are most like those found in Europe, Japan, South America and the USA, these countries may be the origin of L. passim in New Zealand. I would also note, however, that the global distribution of this pathogen is poorly sampled, with limited available information on genetic diversity. Therefore, the New Zealand populations may have also originated elsewhere. The sequences also identified two genotypes present in New Zealand, the genotypes differ by a single nucleotide polymorphism $(\mathrm{A}-\mathrm{C})$. The most prevalent genotype was found throughout New Zealand with the second genotype being detected in a single sample collected from Gore. This result may be due to a sequencing error, as the nucleotide polymorphism is located at the beginning of the sequence. Further sequencing of samples could identify more samples with this genotype or, this one samples presence could represent a low genetic diversity of L. passim in New Zealand. An increase in global studies on trypanosomes is needed to provide more Genbank sequences to elucidate the diversity, origin and evolution of L. passim, C. mellificae and any future trypanosomes detected.

Data was collated over a yearlong period to examine temporal trends in L. passim and other pathogens. Of all pathogens, L. passim is the most prevalent throughout the study. The small reduction seen during the spring and summer period could be a product of growing honey bee numbers in colonies over these months reducing the overall pathogen levels (Higes et al., 2008; Vejnovic et al., 2017). The Christchurch site which had a not detected result in the overview continued to provide samples for the year with levels of L. passim remaining low with the highest levels occurring in May 2017.

What is demonstrated in New Zealand colonies is a high detection rate of $L$. passim which once in the hive remains at high levels throughout the year. In this study several of the colonies were highly infected with L. passim at the end of this study these colonies are reported as continuing to be strong and successful. This may indicate that like bumble bees infected with C. bombi infection in honey bees may produce symptoms, therefore the pathogen may be considered benign (Brown et al., 2003). More specific research into the overall effect of this pathogen on the honey bee is required to draw any conclusions 
Honey bee pathogens do not act in isolation. Within the host honey bee there are many types of pathogens, including the two Nosema spp. and DWV. Pathogen interactions within the host are not well understood, with many studies aimed at developing an understanding of how pathogens react to not only the host but other pathogens (Runckel et al., 2011; Vejnovic et al., 2017). It is important to not look at a single species in isolation which is why this study tested the distribution of N. apis, N. ceranae and DWV in parallel with L. passim.

\section{Nosema in New Zealand}

The overview samples from November 2016 confirm that the two Nosema spp. coinfect honey bees along with L. passim. Of the 23 samples infected with N. ceranae, all are coinfected with $N$. apis. Surprisingly, a single sample from Hastings showed no infection with either of the two Nosema spp. Both Nosema spp. are well distributed throughout the North Island, $N$. ceranae is noticeably absent from South Island samples in this overview. The first confirmed detection of $N$. ceranae in New Zealand was from samples examined by Frazer et al. (2015) previously collected in 2010. Which also identified $N$. ceranae in a sample from the South Island, therefore no detection in my study could be a factor of insufficient sampling, or that populations in the South Island are dwindling. A Swedish study by Forsgren and Fries (2013) demonstrated $N$. ceranae spores exposed to temperatures of $4^{\circ} \mathrm{C}$ exhibited slower germination rates. As the South Island experiences cooler temperatures this could reduce the transmission and germination rates of the spores of $N$. ceranae (Gisder et al., 2010). This pathogen may yet invade the warmer parts of the South Island including Blenheim. This invasion may be facilitated by the movement of honey bee colonies for pollination purposes. Nosema ceranae is a virulent pathogen of honey bees overseas (Higes et al., 2008; Klee et al., 2007), its effects include reduction of life span through energetic deprivation reducing the ability of the bee to forage and return to the hive (Holt and Grozinger, 2016; Martín-Hernández et al., 2011; Schwarz and Evans, 2013). Consequently, it's widespread presence in the North Island and potential effects here make the study of this species a high priority of the apicultural industry.

In comparing the two Nosema spp. N. apis is much more prevalent than N. ceranae in New Zealand, still both species show an increased prevalence in spring the opposite of that seen 
for L. passim in this study. These data are in opposition to many studies from Europe and the United States which demonstrate that N. ceranae is predominant over N. apis which may, in many cases not even be detected (Cepero et al., 2014; Chen et al., 2009; Dainat et al., 2012). This difference could be due to sampling error despite strict collection instructions or a very fast infection rate of the two Nosema spp. in the newly hatched spring bees.

The only other study of N. ceranae and L. passim overtime is from Vejnovic et al. (2017) who detected high levels of $N$. ceranae compared with L. passim in colonies over a year in Serbia. This Serbian study showed seasonal dynamics of $N$. ceranae and L. passim are very similar, both having peak levels in winter along with lows in summer. This pattern was identified to potentially be a factor of having greater numbers of bees in spring, also older overwintering bees carrying a higher pathogen load into winter. My study does not follow these trends or determine a specific peak period, although there is an indication that N. apis and L. passim infection levels are lowest during winter (Figure 4). The Serbian study was however from a single apiary site selected for its level of coinfection. Serbia also has a more extreme climate than New Zealand, with colder winters, which could have also influenced the difference between the studies. To determine if climate is a factor further testing of samples from the South Island should provide a comprehensive data set to confirm the presence or absence of $N$. ceranae in New Zealand and any seasonality.

\section{DWV in New Zealand}

DWV was observed to be the second most prevalent pathogen in my study. This is the main virus associated with colony loss, often a predictor of the colony strength (Cepero et al., 2015; Chen et al., 2009; Ryabov et al., 2014). A study into the cause of CCD from the United States by Dainat et al. (2012) indicated a positive correlation between DWV and $N$. ceranae in colony collapse.

DWV is prevalent in New Zealand and its distribution likely to fluctuate in response to presence of the Varroa mite. Therefore, the variation in DWV levels detected over time could be a factor of mite treatments which may reduce the virus levels as the mite number 
decrease. It would have been ideal in this study to sample Varroa mite abundance at the same time as the pathogens, to understand how mite variation influenced DWV abundance. Different apiarists used different mite control methods (Appendix Two), which may have influenced my results contributing to variation between sites. Varroa, DWV and other pathogens can covary (Cornman et al., 2012; Natsopoulou et al., 2015; Vargas et al., 2017). This pathogen covarying behaviour makes sense because of the overall decline in health a parasite like Varroa can inflict on a hive (Dainat et al., 2012; Le Conte et al., 2010). However, there was no co-variance detected with the other pathogens in this study.

\section{Conclusion}

This study identifies L. passim as the predominant trypanosome currently in New Zealand honey bees, $C$. mellificae was not detected in this study, further testing would be needed to determine if this trypanosome has ever been present in New Zealand. The prevalence and infection levels of L. passim are very high and consistent throughout the study.

Lotmaria passim infection was correlated with the prevalence of other pathogens in an analysis examining data points when pathogen pairs are present (i.e. all 0-vaues removed, Figure 6(b)). It may be that L. passim is influencing the abundance of some pathogens, or vice-versa. However, with such a high prevalence of $N$. apis in this study, similar to findings from Forsgren and Fries (2010) in Sweden this warrants further investigations as it why $N$. apis does so well and has not shown displacement by $N$. ceranae. The pathogen N. ceranae is well-established and widespread in the North Island deserving further analysis due to the effects seen worldwide.

DWV and other pathogens showed no specific trend in temporal population dynamics over the year, due to high variation in levels within and between colonies within regions. A study aimed at test colonies or single hives which can be controlled more stringently especially in relation to mite control may give more resolution on the covariance of the virus in association with L. passim. 
Future studies into L. passim could also include more stringent testing for $C$. mellificae to determine if previously present, present in isolated hives (Eg: the Chatam Island populations) outcompeted by L. passim which is now predominant. Due to the limited number of samples from the South Island it is likely that $N$. ceranae is present, however, if there is variation over time or geographically then this could indicate temperature as a limiting factor to $N$. ceranae in New Zealand and the South Island could become model for testing the effect of pathogens in the absences of $N$. ceranae. 


\section{Bibliography}

Agnew, P., Becnel, J.J., Ebert, D., and Michalakis, Y. (2003). Symbiosis of microsporidia and insects. Insect Symbiosis 1, 145-161.

Aizen, M.A., and Harder, L.D. (2009). The global stock of domesticated honey bees is growing slower than agricultural demand for pollination. Current biology 19, 915-918.

Arismendi, N., Bruna, A., Zapata, N., and Vargas, M. (2016). PCR-specific detection of recently described Lotmaria passim (Trypanosomatidae) in Chilean apiaries. Journal of Invertebrate Pathology 134, 1-5.

Bates, D., Maechler, M., Bolker, B., and Walker, S. (2015). Fitting Linear Mixed-Effects Models Using Ime4. Journal of Statistical Software 67, 1--48.

Benjeddou, M., Leat, N., Allsopp, M., and Davison, S. (2002). Development of infectious transcripts and genome manipulation of Black queen-cell virus of honey bees. Journal of general virology 83, 3139-3146.

Bommarco, R., Kleijn, D., and Potts, S.G. (2013). Ecological intensification: harnessing ecosystem services for food security. Trends in ecology \& evolution 28, 230-238.

Brown (2016). New Zealand Colony Loss Survey. Landcare Research Limited.

Brown, M.J., Schmid-Hempel, R., and Schmid-Hempel, P. (2003). Strong context-dependent virulence in a host-parasite system: reconciling genetic evidence with theory. Journal of Animal Ecology 72, 994-1002.

Bustin, S.A., Benes, V., Garson, J.A., Hellemans, J., Huggett, J., Kubista, M., Mueller, R., Nolan, T., Pfaffl, M.W., and Shipley, G.L. (2009). The MIQE guidelines: minimum information for publication of quantitative real-time PCR experiments. Clinical chemistry 55, 611-622.

Calderone, N.W. (2012). Insect Pollinated Crops, Insect Pollinators and US Agriculture: Trend Analysis of Aggregate Data for the Period 1992-2009. PLOS ONE 7, e37235.

Cavigli, I., Daughenbaugh, K.F., Martin, M., Lerch, M., Banner, K., Garcia, E., Brutscher, L.M., and Flenniken, M.L. (2016). Pathogen prevalence and abundance in honey bee colonies involved in almond pollination. Apidologie 47, 251-266.

Cepero, A., Martín-Hernández, R., Bartolomé, C., Gómez-Moracho, T., Barrios, L., Bernal, J., Teresa Martín, M., Meana, A., and Higes, M. (2015). Passive laboratory surveillance in Spain: pathogens as risk factors for honey bee colony collapse. Journal of Apicultural Research 54, 525-531.

Cepero, A., Ravoet, J., Gómez-Moracho, T., Bernal, J.L., Del Nozal, M.J., Bartolomé, C., Maside, X., Meana, A., González-Porto, A.V., and de Graaf, D.C. (2014). Holistic screening of collapsing honey bee colonies in Spain: a case study. BioMed Central Research Notes 7, 649.

Cersini, A., Antognetti, V., Conti, R., Velletrani, F., and Formato, G. (2015). First PCR isolation of Crithidia mellificae (Euglenozoa: Trypanosomatidae) in Apis mellifera (Hymenoptera: Apidae) in Italy. Fragmenta Entomologica 47, 45-49.

Chan, C.W., Deadman, B.J., Manley-Harris, M., Wilkins, A.L., Alber, D.G., and Harry, E. (2013). Analysis of the flavonoid component of bioactive New Zealand mānuka (Leptospermum scoparium) honey and the isolation, characterisation and synthesis of an unusual pyrrole. Food chemistry 141, 1772-1781. 
Chantawannakul, P., Ward, L., Boonham, N., and Brown, M. (2006). A scientific note on the detection of honeybee viruses using real-time PCR (TaqMan) in Varroa mites collected from a Thai honeybee (Apis mellifera) apiary. Journal of invertebrate pathology 91, 69-73.

Chen, Y., Evans, J.D., Zhou, L., Boncristiani, H., Kimura, K., Xiao, T., Litkowski, A., and Pettis, J.S. (2009). Asymmetrical coexistence of Nosema ceranae and Nosema apis in honey bees. Journal of invertebrate pathology 101, 204-209.

Committee, P.P. (2014). Briefing on the health of bees. P.P. Committee, ed.

Copley, T.R., and Jabaji, S.H. (2012). Honeybee glands as possible infection reservoirs of Nosema ceranae and Nosema apis in naturally infected forager bees. Journal of Applied Microbiology 112, 15-24.

Cornman, R.S., Tarpy, D.R., Chen, Y., Jeffreys, L., Lopez, D., Pettis, J.S., and Evans, J.D. (2012). Pathogen webs in collapsing honey bee colonies. PloS one 7, e43562.

Cox-Foster, D.L., Conlan, S., Holmes, E.C., Palacios, G., Evans, J.D., Moran, N.A., Quan, P.-L., Briese, T., Hornig, M., and Geiser, D.M. (2007). A metagenomic survey of microbes in honey bee colony collapse disorder. Science 318, 283-287.

Dainat, B., Evans, J.D., Chen, Y.P., Gauthier, L., and Neumann, P. (2012). Predictive Markers of Honey Bee Colony Collapse. PLOS ONE 7, e32151.

De Miranda, J., Drebot, M., Tyler, S., Shen, M., Cameron, C., Stoltz, D., and Camazine, S. (2004). Complete nucleotide sequence of Kashmir bee virus and comparison with acute bee paralysis virus. Journal of General Virology 85, 2263-2270.

De Miranda, J.R., and Genersch, E. (2010). Deformed wing virus. Journal of invertebrate pathology 103, S48-S61.

Donovan, B.J. (2007). Apoidea (Insecta: Hymenoptera). Fauna of New Zealand 57.

Evans, J.D. (2001). Genetic evidence for coinfection of honey bees by acute bee paralysis and Kashmir bee viruses. Journal of Invertebrate Pathology 78, 189-193.

Evans, J.D., Saegerman, C., Mullin, C., Haubruge, E., Nguyen, B.K., Frazier, M., Frazier, J., Cox-Foster, D., Chen, Y., and Underwood, R. (2009). Colony collapse disorder: a descriptive study. PloS one 4 , e6481.

Evans, J.D., and Schwarz, R.S. (2011). Bees brought to their knees: microbes affecting honey bee health. Trends in Microbiology 19, 614-620.

Evans, J.D., Schwarz, R.S., Chen, Y.P., Budge, G., Cornman, R.S., De la Rua, P., de Miranda, J.R., Foret, S., Foster, L., and Gauthier, L. (2013). Standard methods for molecular research in Apis mellifera. Journal of apicultural research 52, 1-54.

Forsgren, E., and Fries, I. (2010). Comparative virulence of Nosema ceranae and Nosema apis in individual European honey bees. Veterinary parasitology 170, 212-217.

Forsgren, E., and Fries, I. (2013). Temporal study of Nosema spp. in a cold climate. Environmental microbiology reports 5, 78-82.

Fox, J., and Weisberg, S. (2011). An R companion to applied regression (Sage Publications).

Frazer, J.L., Tham, K.-M., Reid, M., van Andel, M., McFadden, A.M., Forsgren, E., Pettis, J.S., and Pharo, H. (2015). First detection of Nosema ceranae in New Zealand honey bees. Journal of Apicultural Research 54, 358-365.

Fries, I., Feng, F., da Silva, A., Slemenda, S.B., and Pieniazek, N.J. (1996). Nosema ceranae n. sp.(Microspora, Nosematidae), morphological and molecular characterization of a 
microsporidian parasite of the Asian honey bee Apis cerana (Hymenoptera, Apidae). European Journal of Protistology 32, 356-365.

Fries, I., Martin, R., Meana, A., Garcia-Palencia, P., and Higes, M. (2006). Natural infections of Nosema ceranae in European honey bees. Journal of Apicultural Research 45, 230-233.

Gallai, N., Salles, J.-M., Settele, J., and Vaissière, B.E. (2009). Economic valuation of the vulnerability of world agriculture confronted with pollinator decline. Ecological economics 68, 810-821.

Gisder, S., Hedtke, K., Möckel, N., Frielitz, M.-C., Linde, A., and Genersch, E. (2010). Five-year cohort study of Nosema spp. in Germany: does climate shape virulence and assertiveness of Nosema ceranae? Applied and environmental microbiology 76, 3032-3038.

Gisder, S., Schüler, V., Horchler, L.L., Groth, D., and Genersch, E. (2017). Long-Term Temporal Trends of Nosema spp. Infection Prevalence in Northeast Germany: Continuous Spread of Nosema ceranae, an Emerging Pathogen of Honey Bees (Apis mellifera), but No General Replacement of Nosema apis. Frontiers in cellular and infection microbiology 7, 301.

Gomez-Moracho, T., Heeb, P., and Lihoreau, M. (2017). Effects of parasites and pathogens on bee cognition. Ecological Entomology 42, 51-64.

Goodwin, R.M. (2004). Introduction and spread of varroa in New Zealand. Bee world 85, 26-28.

Graystock, P., Goulson, D., and Hughes, W.O. (2015). Parasites in bloom: flowers aid dispersal and transmission of pollinator parasites within and between bee species. In Proceeding in the Royal Society B: Biological Science (The Royal Society), p. 20151371.

Grissell, E. (2010). Bees, Wasps, and Ants: The Indispensable Role of Hymenoptera in Gardens (Timber Press).

Higes, M., Esperón, F., and Sánchez-Vizcaíno, J. (2007a). First report of black queen-cell virus detection in honey bees (Apis mellifera) in Spain. Spanish Journal of Agricultural Research 5, 322-325.

Higes, M., García-Palencia, P., Martín-Hernández, R., and Meana, A. (2007b). Experimental infection of Apis mellifera honeybees with Nosema ceranae (Microsporidia). Journal of invertebrate pathology 94, 211-217.

Higes, M., Martín-Hernández, R., Botías, C., Bailón, E.G., González-Porto, A.V., Barrios, L., Del Nozal, M.J., Bernal, J.L., Jiménez, J.J., and Palencia, P.G. (2008). How natural infection by Nosema ceranae causes honeybee colony collapse. Environmental microbiology 10, 2659-2669.

Holt, H.L., and Grozinger, C.M. (2016). Approaches and challenges to managing Nosema (Microspora: Nosematidae) parasites in honey bee (Hymenoptera: Apidae) colonies. Journal of economic entomology 109, 1487-1503.

Hothorn, T., Bretz, F., and Westfall, P. (2008). Simultaneous Inference in General Parametric Models. Biometrical Journal 50, 346-363.

Jukes, T.H., and Cantor, C.R. (1969). Evolution of protein molecules. Mammalian protein metabolism 3, 132.

Klee, J., Besana, A.M., Genersch, E., Gisder, S., Nanetti, A., Tam, D.Q., Chinh, T.X., Puerta, F., Ruz, J.M., and Kryger, P. (2007). Widespread dispersal of the microsporidian Nosema ceranae, an emergent pathogen of the western honey bee, Apis mellifera. Journal of invertebrate pathology 96, 1-10.

Klein, A.-M., Vaissière, B.E., Cane, J.H., Steffan-Dewenter, I., Cunningham, S.A., Kremen, C., and Tscharntke, T. (2007). Importance of pollinators in changing landscapes for world crops. Proceedings of the Royal Society B: Biological Sciences 274, 303. 
Klein, A.M., Brittain, C., Hendrix, S.D., Thorp, R., Williams, N., and Kremen, C. (2012). Wild pollination services to California almond rely on semi-natural habitat. Journal of Applied Ecology 49, 723-732.

Koch, H., and Schmid-Hempel, P. (2011). Socially transmitted gut microbiota protect bumble bees against an intestinal parasite. Proceedings of the National Academy of Sciences 108, 1928819292.

Kumar, S., Stecher, G., and Tamura, K. (2016). MEGA7: molecular evolutionary genetics analysis version 7.0 for bigger datasets. Molecular biology and evolution 33, 1870-1874.

Langridge, D.F., and McGhee, R.B. (1967). Crithidia mellificae n. sp. an Acidophilic Trypanosomatid of the Honey Bee Apis mellifera. The Journal of Protozoology 14, 485-487.

Lanzi, G., de Miranda, J.R., Boniotti, M.B., Cameron, C.E., Lavazza, A., Capucci, L., Camazine, S.M., and Rossi, C. (2006). Molecular and biological characterization of deformed wing virus of honeybees (Apis mellifera L.). Journal of virology 80, 4998-5009.

Le Conte, Y., Ellis, M., and Ritter, W. (2010). Varroa mites and honey bee health: can Varroa explain part of the colony losses? Apidologie 41, 353-363.

Li, W., Evans, J.D., Huang, Q., Rodríguez-García, C., Liu, J., Hamilton, M., Grozinger, C.M., Webster, T.C., Su, S., and Chen, Y.P. (2016). Silencing the Honey Bee (Apis mellifera) Naked Cuticle Gene (nkd) Improves Host Immune Function and Reduces Nosema ceranae Infections. Applied and environmental microbiology 82, 6779-6787.

Loidl, A., and Crailsheim, K. (2001). Free fatty acids digested from pollen and triolein in the honeybee (Apis mellifera carnica Pollmann) midgut. Journal of Comparative Physiology B: Biochemical, Systemic, and Environmental Physiology 171, 313-319.

Mangiafico, S. (2016). Summary and analysis of extension program evaluation in R. New Brunswick, NJ: Rutgers 442.

Martín-Hernández, R., Botías, C., Barrios, L., Martínez-Salvador, A., Meana, A., Mayack, C., and Higes, M. (2011). Comparison of the energetic stress associated with experimental Nosema ceranae and Nosema apis infection of honeybees (Apis mellifera). Parasitology research 109, 605-612.

Martin, S.J., Highfield, A.C., Brettell, L., Villalobos, E.M., Budge, G.E., Powell, M., Nikaido, S., and Schroeder, D.C. (2012). Global honey bee viral landscape altered by a parasitic mite. Science $336,1304-1306$.

Matheson, A., and Reid, M. (2011). Practical Beekeeping in New Zealand: The Definitive Guide: Completely Revised and Updated (Exisle Publishing Pty Limited).

McFadden A, M.J.B.O.G.R.M. (2016). Investigation of bee mortality in a beekeeper operation in the Coromandel district, Vol 43 (Ministry for Primary Industries).

Meixner, M.D. (2010). A historical review of managed honey bee populations in Europe and the United States and the factors that may affect them. Journal of invertebrate pathology 103, S80-S95.

Mondet, F., de Miranda, J.R., Kretzschmar, A., Le Conte, Y., and Mercer, A.R. (2014). On the front line: quantitative virus dynamics in honeybee (Apis mellifera L.) colonies along a new expansion front of the parasite Varroa destructor. PLoS pathogens 10, e1004323.

Morimoto, T., Kojima, Y., Yoshiyama, M., Kimura, K., Yang, B., and Kadowaki, T. (2012). Molecular Identification of Chronic bee paralysis virus Infection in Apis mellifera Colonies in Japan. Viruses 4, 1093-1103. 
Moritz, R.F., Härtel, S., and Neumann, P. (2005). Global invasions of the western honeybee (Apis mellifera) and the consequences for biodiversity. Ecoscience 12, 289-301.

Murray, Z.L., and Lester, P.J. (2015). Confirmation of Nosema ceranae in New Zealand and a phylogenetic comparison of Nosema spp. strains. Journal of Apicultural Research 54, 101104.

Natsopoulou, M.E., McMahon, D.P., Doublet, V., Bryden, J., and Paxton, R.J. (2015). Interspecific competition in honeybee intracellular gut parasites is asymmetric and favours the spread of an emerging infectious disease. In Proc. R. Soc. B (The Royal Society), p. 20141896.

Oldroyd, B.P. (2007). What's Killing American Honey Bees? PLOS Biology 5, e168.

Olivier, V., Blanchard, P., Chaouch, S., Lallemand, P., Schurr, F., Celle, O., Dubois, E., Tordo, N., Thiéry, R., and Houlgatte, R. (2008). Molecular characterisation and phylogenetic analysis of Chronic bee paralysis virus, a honey bee virus. Virus research 132, 59-68.

Page, R.E., Scheiner, R., Erber, J., and Amdam, G.V. (2006). The Development and Evolution of Division of Labor and Foraging Specialization in a Social Insect (Apis mellifera L.). Current topics in developmental biology 74, 253-286.

Paxton, R.J., Klee, J., Korpela, S., and Fries, I. (2007). Nosema ceranae has infected Apis mellifera in Europe since at least 1998 and may be more virulent than Nosema apis. Apidologie 38, 558565.

Peterson, B.G., Carl, P., Boudt, K., Bennett, R., Ulrich, J., Zivot, E., Lesstel, M., Balkissoon, K., and Wuertz, D. (2014). PerformanceAnalytics: Econometric tools for performance and risk analysis. $R$ package version 1.4. 3541.

Pfaffl, M.W. (2001). A new mathematical model for relative quantification in real-time RT-PCR. Nucleic acids research 29, e45-e45.

Pinheiro, J., Bates, D., DebRoy, S., Sarkar, D., and Team, R.C. (2016). Linear and Nonlinear Mixed Effects Models: R package version 3.1-128; 2016. Google Scholar.

Potts, S.G., Biesmeijer, J.C., Kremen, C., Neumann, P., Schweiger, O., and Kunin, W.E. (2010). Global pollinator declines: trends, impacts and drivers. Trends in Ecology \& Evolution 25, 345-353.

Ravoet, J., Maharramov, J., Meeus, I., De Smet, L., Wenseleers, T., Smagghe, G., and De Graaf, D.C. (2013). Comprehensive bee pathogen screening in Belgium reveals Crithidia mellificae as a new contributory factor to winter mortality. PLoS One 8, e72443.

Ravoet, J., Schwarz, R.S., Descamps, T., Yañez, O., Tozkar, C.O., Martin-Hernandez, R., Bartolomé, C., De Smet, L., Higes, M., and Wenseleers, T. (2015). Differential diagnosis of the honey bee trypanosomatids Crithidia mellificae and Lotmaria passim. Journal of Invertebrate Pathology 130, 21-27.

Ribiere, M., Lallemand, P., Iscache, A.-L., Schurr, F., Celle, O., Blanchard, P., Olivier, V., and Faucon, J.-P. (2007). Spread of infectious chronic bee paralysis virus by honeybee (Apis mellifera L.) feces. Applied and environmental microbiology 73, 7711-7716.

Ribière, M., Triboulot, C., Mathieu, L., Aurières, C., Faucon, J.-P., and Pépin, M. (2002). Molecular diagnosis of chronic bee paralysis virus infection. Apidologie 33, 339-351.

Rosenkranz, P., Aumeier, P., and Ziegelmann, B. (2010). Biology and control of Varroa destructor. Journal of invertebrate pathology 103, S96-S119.

Runckel, C., Flenniken, M.L., Engel, J.C., Ruby, J.G., Ganem, D., Andino, R., and DeRisi, J.L. (2011). Temporal analysis of the honey bee microbiome reveals four novel viruses and seasonal prevalence of known viruses, Nosema, and Crithidia. PloS One 6, e20656. 
Ryabov, E.V., Wood, G.R., Fannon, J.M., Moore, J.D., Bull, J.C., Chandler, D., Mead, A., Burroughs, N., and Evans, D.J. (2014). A virulent strain of deformed wing virus (DWV) of honeybees (Apis mellifera) prevails after Varroa destructor-mediated, or in vitro, transmission. PLoS pathogens 10, e1004230.

Schwarz, R.S., Bauchan, G.R., Murphy, C.A., Ravoet, J., de Graaf, D.C., and Evans, J.D. (2015). Characterization of Two Species of Trypanosomatidae from the Honey Bee Apis mellifera: Crithidia mellificae Langridge and McGhee, and Lotmaria passim n. gen., n. sp. Journal of Eukaryotic Microbiology 62, 567-583.

Schwarz, R.S., and Evans, J.D. (2013). Single and mixed-species trypanosome and microsporidia infections elicit distinct, ephemeral cellular and humoral immune responses in honey bees. Developmental \& Comparative Immunology 40, 300-310.

Statistical Package, R. (2009). R: A language and environment for statistical computing. Vienna, Austria: R Foundation for Statistical Computing.

Stevanovic, J., Schwarz, R.S., Vejnovic, B., Evans, J.D., Irwin, R.E., Glavinic, U., and Stanimirovic, Z. (2016). Species-specific diagnostics of Apis mellifera trypanosomatids: A nine-year survey (2007-2015) for trypanosomatids and microsporidians in Serbian honey bees. Journal of invertebrate pathology 139, 6-11.

Stokstad, E. (2007). The case of the empty hives. Science 316, 970-972.

Sumner, D.A., William A. Matthews, Medellín-Azuara, J., and Bradley, A. (2014). The Economic Impacts of the California Almond Industry.

Taylor, S., Wakem, M., Dijkman, G., Alsarraj, M., and Nguyen, M. (2010). A practical approach to RTqPCR-publishing data that conform to the MIQE guidelines. Methods 50, S1-S5.

Team, R.C. (2015). R: A language and environment for statistical computing. R Foundation for Statistical Computing, Vienna, Austria.

Todd, J.H., De Miranda, J.R., and Ball, B.V. (2007). Incidence and molecular characterization of viruses found in dying New Zealand honey bee (Apis mellifera) colonies infested with Varroa destructor. Apidologie 38, 354-367.

Traynor, J. (2017). A History of Almond Pollination in California. Bee World 94, 69-79.

Tritschler, M., Retschnig, G., Yañez, O., Williams, G.R., and Neumann, P. (2017). Host sharing by the honey bee parasites Lotmaria passim and Nosema ceranae. Ecology and Evolution 7, 18501857.

vanEngelsdorp, D., Evans, J.D., Saegerman, C., Mullin, C., Haubruge, E., Nguyen, B.K., Frazier, M., Frazier, J., Cox-Foster, D., Chen, Y., et al. (2009a). Colony Collapse Disorder: A Descriptive Study. PLOS ONE 4, e6481.

vanEngelsdorp, D., Hayes, J., Jr., Underwood, R.M., and Pettis, J. (2009b). A Survey of Honey Bee Colony Losses in the U.S., Fall 2007 to Spring 2008. PLOS ONE 3, e4071.

Vargas, M., Arismendi, N., Riveros, G., Zapata, N., Bruna, A., Vidal, M., Rodríguez, M., and Gerding, M. (2017). Viral and intestinal diseases detected in Apis mellifera in Central and Southern Chile. Chilean journal of agricultural research 77, 243-249.

Vejnovic, B., Stevanovic, J., Schwarz, R.S., Aleksic, N., Mirilovic, M., Jovanovic, N.M., and Stanimirovic, Z. (2017). Quantitative PCR assessment of Lotmaria passim in Apis mellifera colonies co-infected naturally with Nosema ceranae. Journal of invertebrate pathology. 
Wheeler, D., Buck, N., and Evans, J.D. (2006). Expression of insulin pathway genes during the period of caste determination in the honey bee, Apis mellifera. Insect molecular biology 15, 597602.

Winston, M.L. (1991). The biology of the honey bee (harvard university press).

Wright, G.A., Nicolson, S.W., and Shafir, S. (2017). Nutritional Physiology and Ecology of Honey Bees. Annual review of entomology.

Xu, G., Palmer-Young, E., Skyrm, K., Daly, T., Sylvia, M., Averill, A., and Rich, S. (2018). Triplex realtime PCR for detection of Crithidia mellificae and Lotmaria passim in honey bees. Parasitology Research 117, 623-628.

Yang, B., Peng, G., Li, T., and Kadowaki, T. (2013). Molecular and phylogenetic characterization of honey bee viruses, Nosema microsporidia, protozoan parasites, and parasitic mites in China. Ecology and evolution 3, 298-311.

Yourth, C., Brown, M., and Schmid-Hempel, P. (2008). Effects of natal and novel Crithidia bombi (Trypanosomatidae) infections on Bombus terrestris hosts. Insectes sociaux 55, 86-90.

Yourth, C.P., and Schmid-Hempel, P. (2006). Serial passage of the parasite Crithidia bombi within a colony of its host, Bombus terrestris, reduces success in unrelated hosts. Proceedings of the Royal Society of London B: Biological Sciences 273, 655-659. 


\section{Appendix One}

\section{Evaluation of number of honey bees required for extraction}

The first $4 \times 10$ bee samples showed variable Cq data, with two subsets showing very high infection and two low, if only 10 bees were tested individual results could vary greatly. The 40 bee samples showed less variable Cq data, with subsets showing a high infection which is likely a more accurate representative of $4 \times 10$ bee samples. The 80 bee samples also showed a high infection rate. Based on these data 40 bees were selected as they would give the most representative data for the 100 bees collected and there would be sample remaining that can be used for additional testing if required.

\begin{tabular}{|l|c|c|c|c|}
\hline $\begin{array}{l}\text { Samples } \\
\text { Subsets }\end{array}$ & 10 bees (1) & 10 bees (2) & $1 \times 40$ bees & $1 \times 80$ bees \\
\hline Cq & 19.03 & 18.19 & 19.81 & 19.27 \\
& 31.22 & 31.64 & 19.11 & 19.38 \\
& 17.21 & 18.19 & - & - \\
& 23.94 & 30.74 & - & - \\
\hline
\end{tabular}

\section{Standard Curve}

Real-time PCR standard curve for the Trypanosome Kit (dnature) which detects the trypanosomes C. mellificae and L. passim. The graph shows a dilution series from 1:10-1

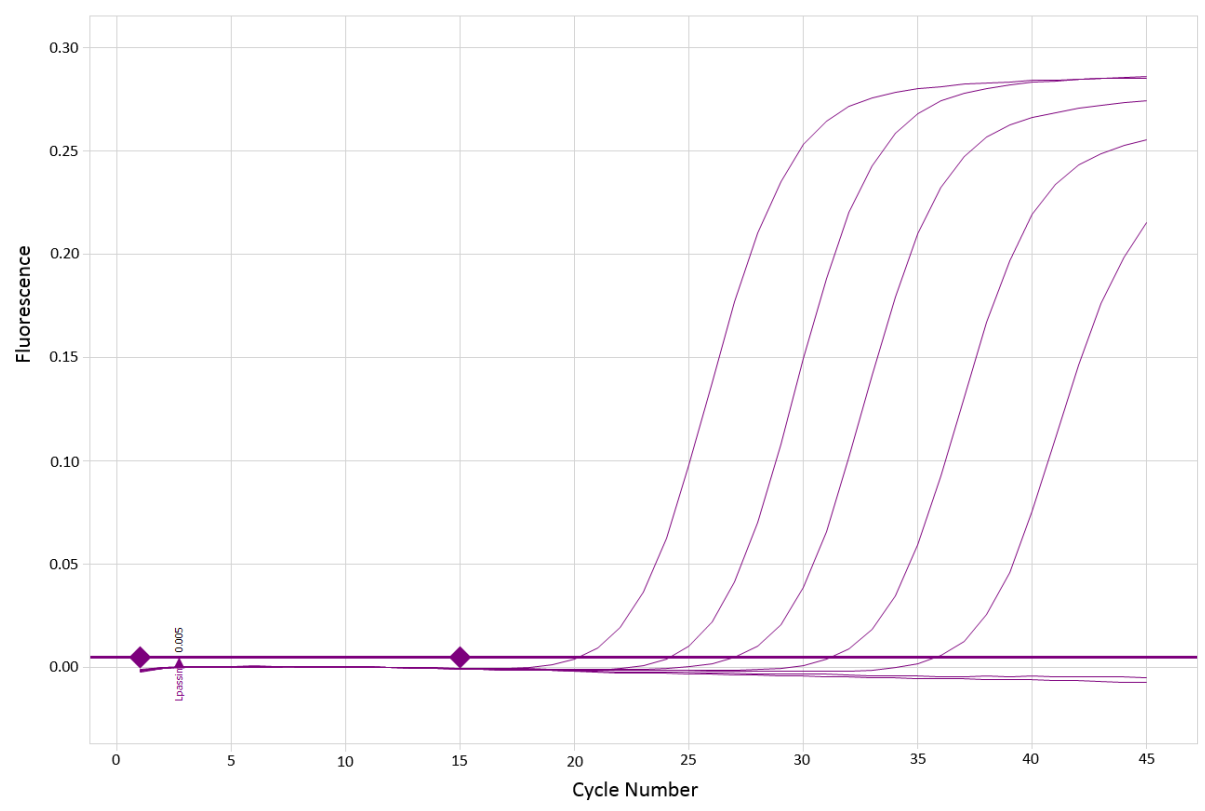


(left) to $1: 10 \mathrm{e}^{-5}$ (right). The standard curves show Cq decreasing (moving to the right) with every dilution as expected, note the curves for each dilution factor are evenly spaced and the efficiency values are shown in table below.

Real-time PCR efficiency by standard curve

Reaction efficiencies, slope and $R^{2}$ values from standard curves generated for this study all of which are within expected limits for robust and precise real-time PCR reactions

\begin{tabular}{|l|c|c|c|}
\hline Pathogen & Reaction Efficiency & Slope & $\mathbf{R}^{\mathbf{2}}$ \\
\hline $\begin{array}{l}\text { Trypanosome (L. passim \& } \\
\text { C. mellificae) }\end{array}$ & $96.37 \%$ & -3.412 & 0.998 \\
\hline N. ceranae & $96.97 \%$ & -3.397 & 0.998 \\
\hline N. apis & $103.92 \%$ & -3.238 & 0.990 \\
\hline B-actin & $99.28 \%$ & -3.339 & 0.992 \\
\hline RPS5 & $97.69 \%$ & -3.379 & 0.997 \\
\hline
\end{tabular}

Real-time PCR sensitivity test

The primer pairs qCRFwd1/Rev1 and Trypanosome Kit (dnature) were compared, the latter being more sensitive due to the detection of lower copy numbers. This is shown in samples $6 \& 8$ which gave not detected results with the primer set qCRFwd1/Rev1 but were detected using the Trypanosome Kit (dnature). Spectrophotometry of the DNA shows that purity of DNA is confirmed in all samples. A "pure" DNA sample using the 260/280 ratio would give 1.8 but between $1.7-2.0$ is acceptable.

\begin{tabular}{|c|c|c|c|c|}
\hline \multirow{2}{*}{ Sample ID } & \multicolumn{2}{|c|}{ Real-time PCR Cq value } & \multicolumn{2}{c|}{ DeNovix DS-11 Spectrophotometer } \\
\cline { 2 - 5 } & $\begin{array}{c}\text { qCrFwd1/Rev1 } \\
\text { primers }\end{array}$ & $\begin{array}{c}\text { Trypanosome Kit } \\
\text { (dnature) }\end{array}$ & $\begin{array}{c}\text { DNA concentration } \\
\text { (ng/ } \mu \text { ) }\end{array}$ & $260 / 280$ ratio \\
\hline 1 & 20.68 & 16.66 & 461.09 & 1.94 \\
\hline 2 & 23.08 & 18.67 & 288.23 & 1.90 \\
\hline 3 & 20.50 & 18.33 & 446.66 & 1.95 \\
\hline 4 & 34.86 & 30.28 & 361.76 & 1.89 \\
\hline 5 & 36.30 & 33.28 & 465.60 & 1.79 \\
\hline 6 & ND & 34.27 & 405.02 & 1.93 \\
\hline 7 & 21.25 & 17.63 & 524.19 & 1.96 \\
\hline 8 & ND & 33.25 & 640.04 & 1.98 \\
\hline
\end{tabular}




\section{Appendix Two}

\section{Sites and Treatments Given}

Details of varroa treatments and feeding at each of the year study sites

\begin{tabular}{|c|c|c|}
\hline Site & Varroa Treatment & Feeding \\
\hline Kaitaia & March 2017 Apivar & November 2017 Sugar Syrup \\
\hline Auckland & $\mathrm{N} / \mathrm{A}$ & N/A \\
\hline Coromandel & $\begin{array}{l}\text { February } 2017 \text { Bayvarol } \\
\text { June } 2017 \text { Thymol }\end{array}$ & $\begin{array}{l}\text { February } 2017 \text { Sugar Syrup } \\
\text { May } 2017 \text { Sugar Syrup } \\
\text { September } 2017 \text { Sugar Syrup }\end{array}$ \\
\hline Te Aroha (2) & March 2017 Bayvarol & $\mathrm{N} / \mathrm{A}$ \\
\hline Te Awamutu & $\begin{array}{l}\text { February } 2017 \text { Oxalic Acid } \\
\text { April } 2017 \text { Oxalic Acid }\end{array}$ & $\mathrm{N} / \mathrm{A}$ \\
\hline Gisborne (2) & $\mathrm{N} / \mathrm{A}$ & $\mathrm{N} / \mathrm{A}$ \\
\hline Turangi & $\begin{array}{l}\text { January } 2017 \text { Oxalic Acid } \\
\text { January } 2017 \text { MAQS } \\
\text { February } 2017 \text { Oxalic Acid \& } \\
\text { Glycerine }\end{array}$ & N/A \\
\hline Hastings & $\mathrm{N} / \mathrm{A}$ & $\mathrm{N} / \mathrm{A}$ \\
\hline Palmerston North & $\begin{array}{l}\text { April } 2017 \text { MAQS } \\
\text { July } 2017 \text { Apivar }\end{array}$ & N/A \\
\hline Wellington & $\begin{array}{l}\text { February } 2017 \text { Bayvarol } \\
\text { May } 2017 \text { Thymovar } \\
\text { September } 2017 \text { Bayvarol \& }\end{array}$ & $\mathrm{N} / \mathrm{A}$ \\
\hline Christchurch M & $\begin{array}{l}\text { February } 2017 \text { Bayvarol } \\
\text { April } 2017 \text { Bayvarol } \\
\text { September } 2017 \text { Apivar }\end{array}$ & N/A \\
\hline Christchurch R & $\begin{array}{l}\text { December } 2016 \text { Oxalic Acid \& } \\
\text { Thymovar }\end{array}$ & $\mathrm{N} / \mathrm{A}$ \\
\hline Dunedin & $\mathrm{N} / \mathrm{A}$ & N/A \\
\hline
\end{tabular}

